\title{
Aesthetic Flexibility \\ Modularity of Visual Form in Product Portfolios and Branded Products
}

\section{Torbjörn Andersson}

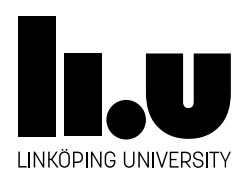

Division of Machine Design

Department of Management and Engineering Linköping University, SE-581 83 Linköping, Sweden

Linköping 2016 
Copyright (C) Torbjörn Andersson, 2016

Aesthetic Flexibility - Modularity of Visual Form in Product Portfolios and Branded Products

ISBN 978-91-7685-741-0

ISSN 0280-7971

Distributed by:

Division of Machine Design

Department of Management nd Engineering

Linköping University

SE-581 83 Linköping, Sweden

Printed in Sweden by LiU-Tryck, Linköping 2016 
IT'S A MAGICAL WORLD. HOBBES, OI' BUDDY

- BILL WATTERSON

LET'S GO EXPLORING! 



\section{ABSTRACT}

Theincrease in competition amongst companies that produce complex or large product portfolios has created a need to utilise modularity strategies not only to flexibly manage technical complexity in a costeffective manner but also for visual appearance. This research aims to understand how the visual appearance of products is affected by modular product development strategies. Specifically, the aim is to understand how such strategies induce constraints and generate possibilities for management of visual appearance in the design process.

Five studies have been conducted during the course of this licentiate thesis. Two were conducted with professionals and students in design, while the remaining three are theoretical studies based on findings in the literature, theory building, and experimental research. The goal has been to investigate how designers work when they are put to the task of changing and developing the designs of complex products that are part of a portfolio. The challenge has been to study what suitable strategies exist that manage complex products and product brands, then investigate how these influence designers' practices.

The first study examined how coherence towards a product category influences the design of new products. The outcome of the study was a method to explore visual coherence and diversity in the appearance of a product category.

The remaining four studies investigated how modularity, brand management and the redesign of product portfolios influence a design process. The second study described a design phenomenon known as aesthetic flexibility, which was further explored in studies three and five. The outcome from these studies was a proposal for four aesthetic flexibility strategies. 
The fourth study investigated in what way portfolio extension strategies found in brand management and design research are related, and how such strategies influence aesthetic flexibility. The results from study four were illustrated as a model.

The main contribution of this work is the phenomenon of 'aesthetic flexibility', which helps understand the factors that influence designers when working with branded modular products. Understanding visual flexibility serves as a starting point in further investigations of how different development strategies affect the possibilities for visual product design.

The findings of this work serve to illustrate and explain a complex and multi-facetted design phenomenon which many designers manage more or less intuitively today, thus advancing academics', teachers' and professional designers' understanding of the field.

Keywords: Aesthetic flexibility, industrial design, product modularity, brand extension, product portfolio development, carry-over, face-lift 


\section{ACKNOWLEDGEMENTS}

The work presented in this thesis was carried out at the Division of Machine Design at the Department of Management and Engineering (IEI) at Linköping University, Sweden.

There are many people I would like to express my gratitude to for making this thesis possible. I would first and foremost like to express my gratitude to my main supervisor, professor Johan Ölvander, for giving me much advice, support and guidance, and for proofreading my efforts during this endeavour.

My supervisor, professor Anders Warell, for all discussions about product form and design research, proofreading and advice on how to structure the thesis. My second supervisor, Stefan Holmlid, for advice regarding design research and when writing papers.

I am also very grateful to all of the interviewees who participated in my studies and who have been the source of much of my research data. Without your thoughts and insights this thesis would not have turned out as well as it did.

I would also like to thank all my new and old colleagues at the Division of Machine Design for supporting me while researching and writing this thesis but most of all for creating a fun and inspiring working environment.

And last but not least, my girlfriend Elin Rungstad for being my main supporter and giving me a lot of love along the way.

Torbjörn Andersson

Linköping, May 2016 



\section{APPENDED PUBLICATIONS}

The appended papers are the basis of this thesis; they are referred to as papers $\mathrm{A}-\mathrm{C}$ in the text. The papers are printed as they were originally published except for format changes.

PAPER A

Andersson T., and Warell A., 2015. Aesthetic flexibility in the management of visual product branding. In: 6th International Conference on Applied Human Factors and Ergonomics and the Affiliated Conferences (AHFE 2015). Las Vegas, Nevada, 26-30 July, 2015

PAPER B

Andersson T., 2014. Workshop in the influence of "Carry over" details on strategic formgiving. In: 13th NORDCODE seminar छ Workshop. Gothenburg, 10-12 September 2014

PAPER C

Andersson T., Warell A., and Holmlid S., 2013. Product gist: An approach to identifying from characteristics of the current product sign. In: 10th European Academy of Design Conference - Crafting the Future. Gothenburg, 17-19 April, 2013 


\section{ADDITIONAL PUBLICATIONS}

Additional publications that were published during the course of the research that are not included or discussed in this licentiate thesis.

Berglund M., Andersson T., Hedbrant J., Pavlasevic V., and Stålhand J., 2015.Understanding the user beyond 'common sense' - Teaching Product Ergonomics to design engineering students. Proceedings 19th Triennial Congress of IEA, Melbourne 9-14, August 2015.

Berglund M., Pavlasevic V., Andersson T., Hedbrant J., and Stålhand J., 2014.Theme-based assessment of education in design and product development. In: 10th International CDIO Conference at Universitat Politécnica de Catalunya, Barcelona June 15-19, 2014.

Andersson T., Warell A., Holmlid S., Ölvander J., 2011. Desirability in the development of In-Car Infotainment Systems, In: 13th IFIP TC13 Conference on Human-Computer Interaction. Lisbon, Portugal September 5-9, 2011. 
O1 INTRODUCTION 1

1.1 Purpose and research questions $\ldots \ldots \ldots \ldots \ldots \ldots \ldots \ldots \ldots \ldots$

1.2 Research aim ......................................... 3

1.3 Outline of the thesis .................................... 4

O2 FRAME OF REFERENCE

2.1 Industrial design in a brand context. .......................6

2.1 .1 Product semantics and design features ................... 9

2.2 Product modularisation and its impact..................... 13

2.3 Redesign and revitalisation. ............................. 15

2.4 Extension of product brands ............................. 17

O3 RESEARCH APPROACH 19

3.1 Research rationale ..................................... 19

3.2 Overall research approach ............................ 20

04 CONDUCTED STUDIES 23

4.1 Study 1 - Product Gist....................................27

4.2 Study 2 - Designer interview study ..................... 30

4.3 Study 3 - Design Workshop "Carry-over"................... 33

4.4 Study 4 - Brand management's influence.....................37

4.5 Study 5 - Investigating aesthetic flexibility ................ 45

05 DISCUSSION 55

5.1 Aesthetic flexibility and its influence on designers' thinking..... 55

5.2 Aesthetic flexibility's influence on a design process ............57

5.3 The influence of brand extension and redesign .............. 58

5.4 Product gist and aesthetic flexibility ..................... 58

5.5 Reflection on the research approach..................... 59

5.6 Limitations ........................................ 61

O6 CONCLUSIONS AND FUTURE WORK 63

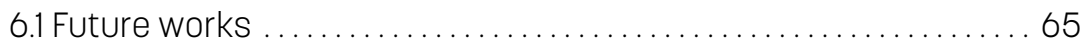

O7 REFERENCES $\quad 67$ 



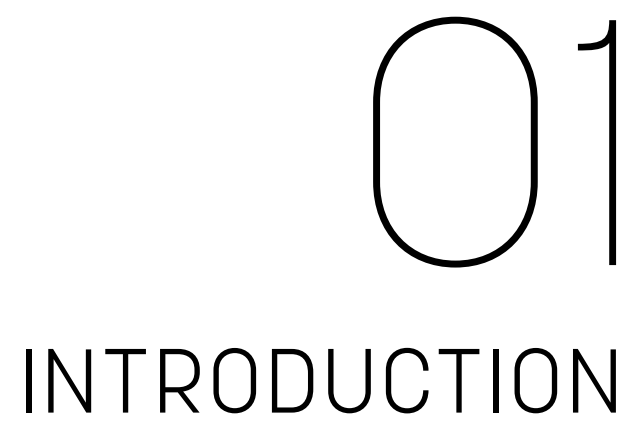

In many of today's global markets, competition amongst companies is tough. A company has to "stay ahead of the game" and at the same time be responsive to changes in the market in order to fend off competitors. This generates pressure on companies to regularlyupdate or redesign their existing product portfolio, expand the portfolio into new markets, and make variants of existing products to increase the company's offering to its customer. Product-producing companies that utilise these strategies, and become successful, typically need to manage a large number of product units that consist of several parts depending on the complexity of the product* (Ulrich 1995). A car for instance has thousands of parts but a screwdriver might only have two. In order to manage large amounts of $\beta$ units and parts, companies have created strategies to harmonize, standardize, and share components across a portfolio. These rationalisat ions reduce costs, time-to-market, and customisation; which are important strategies in order for product-producing companies to compete.

When a company shares parts across its portfolio, this affects the development of distinct design proposals and renders them interdependent upon each other.

* Complex products can be characterised as having many parts, different types of parts, different types of interconnections between the parts, a larger number of interfaces amongst parts and the amount of functions that are shared between the parts (Pugh 1991). 
The interdependence means that several products will be influenced at the same time when shared designs are redesigned. Furthermore, the sharing of parts restricts the degree of freedom industrial designers will have when extending an existing product portfolio due to the need to incorporate existing parts.

Sanchez (2002) suggests that industrial designers need to be involved in synchronising the design effort involved in product portfolios so that a company can benefit from coordination and rationalisation gains in all parts in a portfolio, not only the technical components. One reason for this is that one part of an industrial designer's work is to determine the size, shape, material, colour, texture and user experience of finished products. This generates boundaries that effect technical solutions, layout, and the product assembly.

The design process of redesigning and expanding portfolios, consisting of complex products, is more multi-layered from a design perspective than previously described. Industrial designers need to create new designs and at the same time ensure that rationalisation benefits are treated in a portfolio. This suggests that designing products under these circumstances generates a type of strategic and aesthetic thinking, which needs more flexible approaches to aesthetic thinking in product design. The thesis will explore and illustrate how designers can meet these challenges by making the product designs more flexible.

Findings from this research will increase understanding of how the above-described conditions affect and guide the designer in a design process. Insights will enable development of tools and methods for distributing designs across a portfolio that can contribute to economic gains, shorten time-to-market and maintain the visual coherence of an existing brand. 


\subsection{Purpose and research questions}

The overall purpose of this research is to increase the existing knowledge of how industrial designers work with aesthetic demands created by complex products that are part of a branded product portfolio. More specifically, this research studies what aesthetic strategies emerge when designers extend the portfolio by adding new products or when they redesign products in an existing portfolio. This involves describing and explaining how these strategies influence the development of products where the design is divided up into units and parts, thus creating possibilities to share and evolve only part of a product.

\subsection{Research aim}

In detail this research aims to understand how the complexity and assembly of a product create restrictions for the development of designs and how this influence industrial designers when redesigning or extending a product portfolio. Second, it aims to describe how product-branding influences the previously described processes, due to the interdependence between the product's design and the brand. Finally, this research aims to investigate how designers and managers can investigate what creates coherence within a category of products. This is in order to understand how the coherence influences new designs. The following research questions address these aims:

RQ 1: What design strategies can be employed in order to create visual flexibility in different types of product architectures?

RQ 2: How can the process of redesigning modular products be connected to existing brand extension strategies?

RQ 3: How can the visual characteristics of a product category be identified and used as a support for product categorisation? 


\subsection{Outline of the thesis}

The thesis is structured as follows.

Chapter 1 - Introduction

The first chapter introduces the background to and purpose of the research. Research aims as well as research questions are presented.

Chapter 2 - Theoretical framework

In chapter 2 the theoretical foundation is compiled to frame the research scope, contribution and discussion.

Chapter 3 - Research approach

Chapter 3 describes what research epistemology and scientific methods were used to explore and answer the research questions.

Chapter 4 - Conducted studies

In this chapter results from five different studies are presented and further elaborated.

Chapter 5 - Discussion

In chapter 5, results from the conducted studies and the research methods are discussed and scrutinised with support of the theoretical framework in chapter 2 .

Chapter 6 - Conclusions and future work

In the final chapter, the research questions are answered. Furthermore, proposals are made for new research endeavours to advance the presented findings and results in this thesis further. 


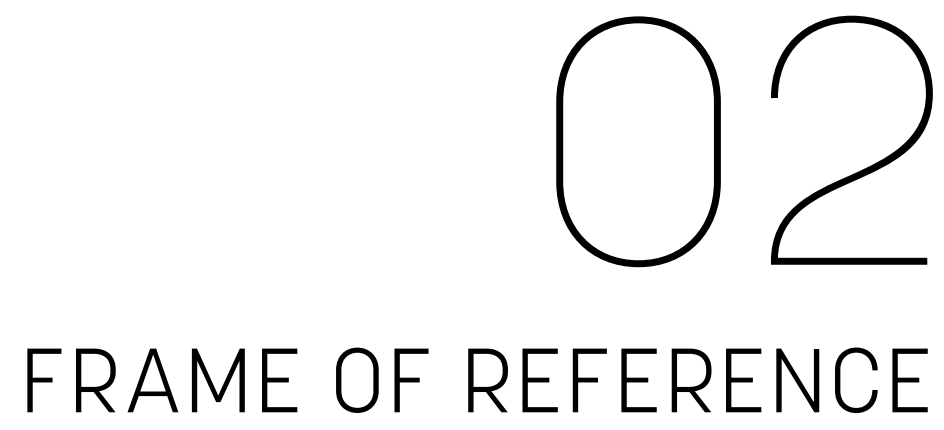

This chapter describes the theoretical foundation used to develop the research scope and to frame the contributions to design research in this thesis.

Several different theoretical areas of academic knowledge have been investigated in addressing the research purpose and to understand the empirical results. On an overall perspective, existing literature on product design (with a focus on redesign), how it relates to brand management (in particular brand extension literature), and the role product modularity plays when products are redesigned or when product portfolios are extended. The areas of study are shown in figure 1 . The lines describe how different knowledge areas interact with each other. The thick lines indicate that the interplay between the areas is discussed within this thesis and thin lines represent the fact that the literature has a supportive role.

Industrial design in a brand context and Product semantics E design features are discussed first in order to provide a general understanding of what influences product design of branded products. Product Modularisations impact on product design is then examined to frame how increased complexity influences the product design process. Lastly, Redesign of Branded Products and Extension of Product Brands is examined to describe two common strategies a designer utilises to further develop a product portfolio. 


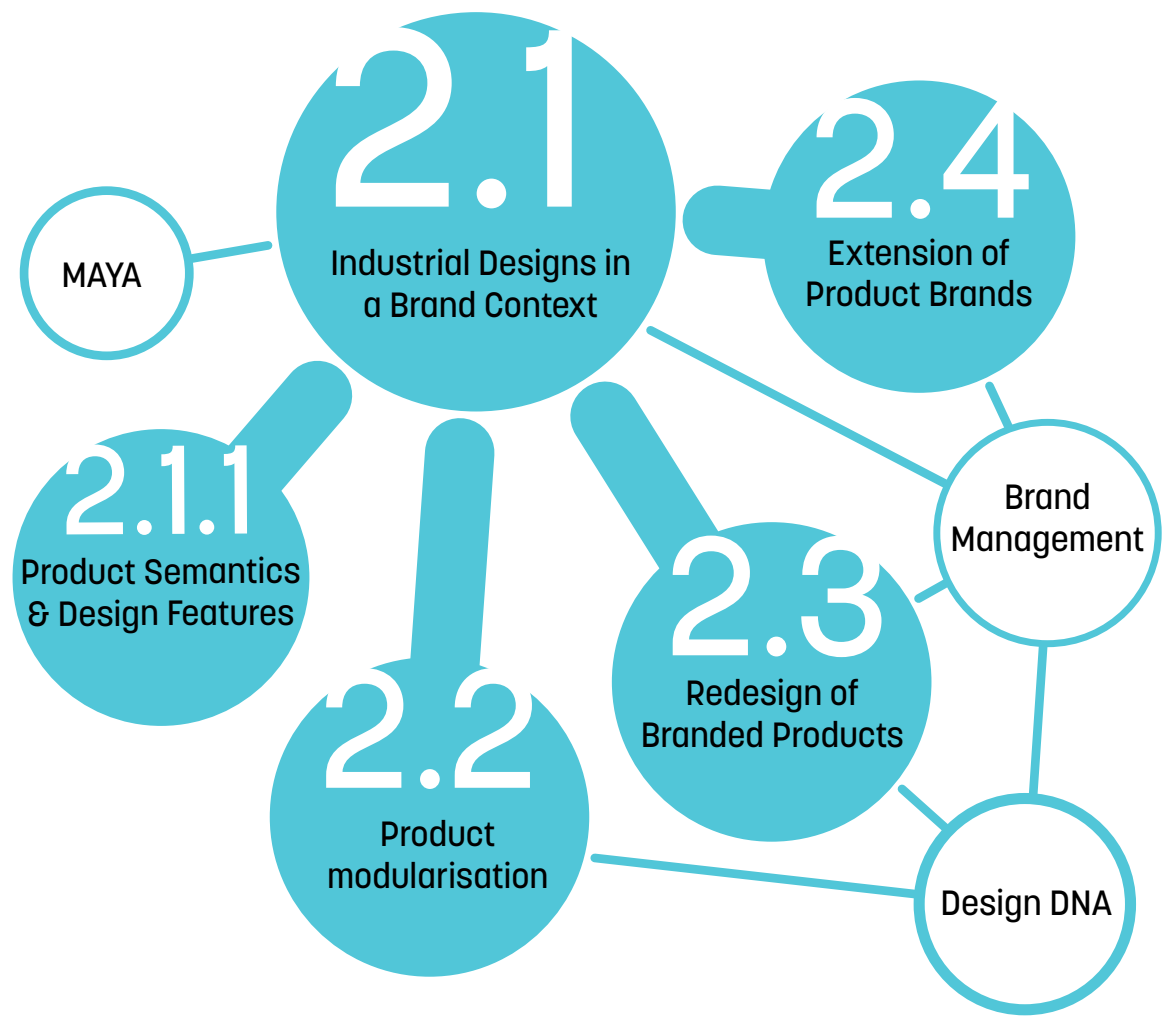

Figure 1. Illustration of theoretical subjects investigated and how they relate to the main subject, i.e. understanding what influences an industrial designer when working with branded, modularised product portfolios.

\subsection{Industrial design in a brand context}

Kapferer (2012) states that there are two main ways of reasoning for an industrial designer when developing a branded product portfolio; the first is branded house and the second is house of brands. In a "branded house" strategy, industrial designers' undertaking is to coordinate all design efforts and create a unified communication towards its customers and a coherent visual recognition across all of its products. An example of a "branded house" company is Hilti hand-tools (Hilti, 2016), who have created a unified brand identity 
and coordinated all their products using the same colour scheme, texture, materials and recognisable design features. In a "house of brands", on the other hand, a company manages several different brands with unique designs in its portfolio. Here, the design effort focuses on maintaining visual diversity and alignment between the different brands rather than a communal "house".

While both strategies are successful, the research scope however focuses on the branded house strategy since these portfolios strive to align products, thus creating incentives for industrial designers to plan the design and utilise modularisation methods.

Besides aligning the products in a branded house portfolio, an industrial designer also has to make a design "stand out from the crowd" (Kotler \& Rath, 2007). According to Person et al. (2007), Schoormans \& Robben (1997) and Karjalainen \& Snelder (2009), product design in commercial markets has to attract attention in order to be noticed by consumers, thus giving a possibility to create recognition towards a brand. Warell (2006) and Arvola et al., (2010) state that a product can create recognition mainly through our perception and this is based on what resemblances or similarity it imposes as regards prior knowledge of the product. Another way to create recognition in a design is to differentiate against competitors through deviating the products; this is done through creating an understating of what the product is not (Karjalainen, 2009; Kippendorf, 1989). For instance, a Lamborghini is a car but does not look and behave like a Volvo XC90, which is recognised as an SUV and not a sports car.

Raymond Loewy (1988) was the first industrial designer to describe this balance between standing out/differentiation and recognition in a product segment by coining the term 'Most Advanced, yet Acceptable' or MAYA for short. Loewy described it as a means of finding the commercial 'sweet-spot' in a product design. Keller et al. (2012) demonstrate that the same considerations are relevant in management of brands and their portfolios. The authors state that brands need to create point of difference (POD) and point of parity (POP) as means to be successful. 
Keller et al. (2012) define Point Of Difference as “...strong, favourable and unique associations..." (ibid) that consumers relate to the product portfolio and the company brand and which would not be found in a competing brand. POD is equivalent to Loewy's (1988) 'Most Advanced', meaning that a product has to be more revolutionary than its competitors. Keller et al. (2012) also state that a way of developing into a strong brand is to utilise the company's history and evolutionarily develop positive POD associations. (Warell, 2006; Karjalainen \& Snelder, 2010; Kapferer 2012).

A more common name for POD is Design DNA. This refers to when a company has successfully built coherence and positive associations over time and developed a set of characteristics that are unique to a specific brand (Hestad, 2014; Person \& Snelder, 2009). The idea of DNA as a metaphor for incremental development of design became popular in the early 2000s and refers to the Darwinian theory of evolution according to Person \& Snelders (2009). Defining and utilising Design DNA characteristics is an important undertaking for companies in streamlining their visual communication and product recognition. Person et al. (2008) describe this strategic development as creating a consistent and distinct brand image by having: "(1) to facilitate recognition and (2) to transfer beliefs that consumers have concerning one product to another falling under the same brand name."

Point Of Parity, on the other hand, is described as those "associations that may be shared with other brands". Keller et al. (2012) divide POP into two forms: Category POP and Competitive POP. Category POP is related to Yet Accepted in MAYA (Loewy, 1988) and is described as associations that are essential for a brand to create recognition against a category of similar products. For most companies, it can be equally important to belong to a strong category, as it is being perceived as unique (Monö 1997; Kreuzbauer 2007; Goode et al. 2013; Kapferer 2012; Andersson et al. 2013; Ranscombe et al. 2012). In competitive situations, POP can also be utilised as a strategic way of 'defusing' rival PODs by creating similar brand associations in order to make them 'break even' (Keller et al. 2012). 
For instance, today the leading smartphone brands look and interact in a very similar way. This makes POD and POP important strategies when industrial designers develop how consumers perceive a company's brand through its products.

\subsubsection{Product semantics and design features}

The term product semantics was coined by Krippendorff \& Butter in 1984 and connotes "...the study of the symbolic qualities of man-made forms in the context of their use and application of this knowledge to industrial design". This means that when a designer makes a product (or 'man-made form') for a company, they simultaneously creates a sign that then is interpreted by consumers. Karjalainen \& Snelder (2010) build on this definition and apply Piercean semantic theory to the design of products. According to Peirce (1955) a sign is built upon a triadic interplay between a Representamen $(\mathrm{R})$, an Object $(\mathrm{O})$ and an Interpretant (I). Chandler (2007) describes the three components as:

1. The representamen: the form which the sign takes (not necessarily material, though usually interpreted as such).

2. An interpretant: not an interpreter but rather the sense made of the sign.

3. An object: something beyond the sign to which it refers (a referent).

Karjalainen \& Snelder (2010) utilises the Piercean semantic theory and state that brand values $(\mathrm{O})$ can be manifested in product properties or design features (R) in order to create a meaning (I) of the sign. Furthermore, the relationship between $(R)$ and $(O)$ is "stringed" or coupled, meaning that design features and brand values are interconnected through the associations they transfer between each other (figure 2). Karjalainen \& Snelder (2010) states that“... design features create associations that connect the product with specific brand values, and, at the same time, the brand values and 
their historical representations strongly affect the interpretation of the design features."

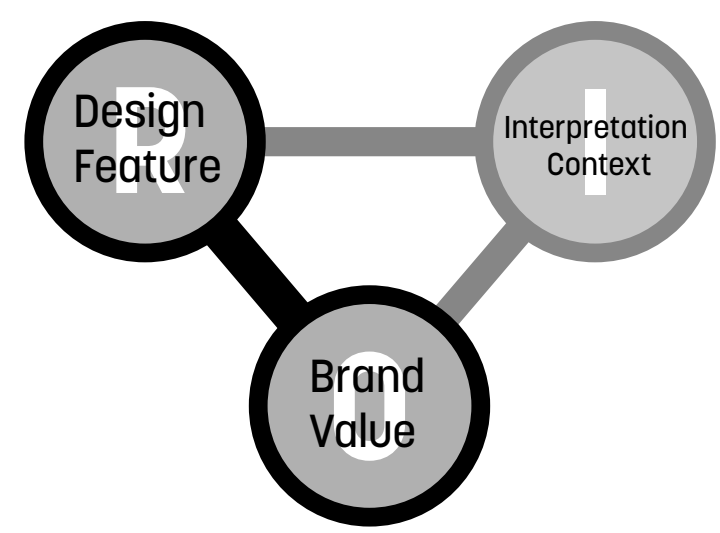

Figure 2. The R-O-I model, illustrating how design features and brand value are linked to Pierce semantic theory, Karjalainen छீ Snelders (2010).

Karjalainen \& Snelder's (2010) R-O-I model shows that when industrial designers create new or redesign existing products for modular portfolios they have to take into account how the brand values will be influenced. Brand value $(\mathrm{O})$ is connected to it through design features $(\mathrm{R})$. The brand value may also be shared between products. This sharing has to be supervised so that the interpretation (I) of the brand is not damaged through value clashes in the mixing of designed modules.

Design features are the 'building blocks' that designers utilise when creating attention towards a product through sensory effects, imposing brand identity, and to create visual coherence throughout a portfolio (Hollins \& Pugh 1990; Lewalski 1988; Warell 2006; Karjalainen \& Snelder 2010; Ranscombe 2012; Person et al. (2007). A design feature can be both explicit and implicit according to Karjalainen, (2004) and Kapferer (2014 p 38-43).

Explicit refers to tangible features of products that create visual recognition towards a brand and differentiate the products from its competitors. This definition shows strong resemblance with Keller et al.'s (2012) model of POD. Researchers (Warell 2002, 2006; Monö 
1997; Sanchez 2002; Karjalainen \& Snelder 2010) have recognized that designers work strategically with these features when they want to create coherence throughout a product portfolio. Sharing design features across a portfolio increases brand recognition and creates visual discrepancy towards competitors. An explicit feature has the intent to be immediately perceived as belonging to a specific brand, like the kidney grille and the Hofmeister Kink on a BMW car. What Karjalainen (2004) and Kapferer (2014, p.38-43) do not address are explicit features connected to the category (POP) or "the current product sign" as described by Monö (1997). These types of explicit features are necessary in order to link the brand to a product category.

Implicit design features have the objective to be unconsciously perceived, the overall feeling or the "gist" of a product that for instance stipulates "This is a BMW" (Karjalainen 2004; Kippendorff 1989; Andersson 2013). These types of features are harder to define and are therefore described more generally in the literature. They are described as being emotionally and behaviourally driven features where the interpreters' prior knowledge plays an important part in the decoding of the features.

To exemplify how design features are described in the literature, a table was constructed (Table 1). The features found were organised through affiliation with the two described design feature categories, i.e. explicit and implicit. Hestad's (2014) description of design features (the left-hand column in the table) was used as a basis in organising the found explicit features. Implicit features are organised by compiling the literature findings. The table is used to obtain an overview of what the compiled literature says about design features and show how they influence a product's design.

This shows that the creation of a design has direct impact on a company's brand and that the processes of creating competitive designs are similar to those of creating differentiation between brands. The design features found in the literature indicate that there are several ways an industrial designer can influence or change the meaning of a brand; both explicitly and implicitly. 


\section{Explicit Features}

\begin{tabular}{l|l} 
Main Form & $\begin{array}{l}\text { Shape, Silhouette, Proportion, } \\
\text { Scale, Pattern of Organisation }\end{array}$ \\
\hline Details & Lines, Ornamentation \\
\hline Finish & Reflectiveness, Texture \\
\hline Graphics & $\begin{array}{l}\text { Logotype, Graphical Elements, } \\
\text { Symbols }\end{array}$ \\
\hline Colour & $\begin{array}{l}\text { What associations different } \\
\text { materials exhort. }\end{array}$ \\
\hline Materials & $\begin{array}{l}\text { Many products have interfaces } \\
\text { that consumers interact with. }\end{array}$ \\
\hline Graphical User Interfaces & \begin{tabular}{l} 
Features \\
\hline Implicit
\end{tabular}
\end{tabular}

\begin{tabular}{l|l} 
Gist & Whole apperance. \\
\hline Differentiation & What the product should not be. \\
\hline Brand Story & $\begin{array}{l}\text { The product's role in the brand } \\
\text { and how to realise it. }\end{array}$ \\
\hline Emotional Associations & $\begin{array}{l}\text { How the product evokes emotions } \\
\text { in consumers. }\end{array}$ \\
\hline Characteristic Behaviour & $\begin{array}{l}\text { How the product interacts with } \\
\text { users and/or other products. }\end{array}$
\end{tabular}

Table 1. Tables showing design characteristics found in the literature from: Hestad 2014, p. 65; Davis 1987; Bloch P. 1995; Kellaris छ Kent 1993; Kippendorff 1989; Keller et al 2012; Klimchuck छ Krasovec 2012, p. 155. 
A product's construction and layout impact how restricted an industrial designer can be in the development of a new design. This becomes particularly clear when designers work with complex products that are exposed to competition. Complexity makes it difficult to make a lot of changes to a product but at the same time competition creates a need to update and modify the products in order to compete. According to Ulrich \& Eppinger (2012) and Sanchez (2002) and Diffner (2011), companies that have complex products strive to rationalize as much as possible to be able to respond more rapidly to changes in the market and cut costs through economy of scale. To meet this demand for changes in complex products, companies' product managers organize the parts of a product into modules (Ulrich, 1995). Modules are described as having both physical- and functional elements (Ulrich \& Eppinger 2012, Sanchez 2002 and Kusiak \& Huang 1996).

Physical elements are all the components, parts, and subassemblies that make up the whole product. This means that some modules will be part of the design and thus have design features incorporated. Functional elements refer to how a product is operated and how it can transform or influence its surrounding. According to Ulrich (1995), modularising of a product needs to be conducted in at least three phases.

First, all functional elements need to be identified, arranged, and clustered into groups. Second, the functions and function-groups are then mapped with physical elements, thus creating modules. The last step is to specify how the interfaces should be designed between the components and modules. The specification of interfaces is important because it makes it possible to change one module without needing to change the whole product. All three phases are illustrated in figure 3. 


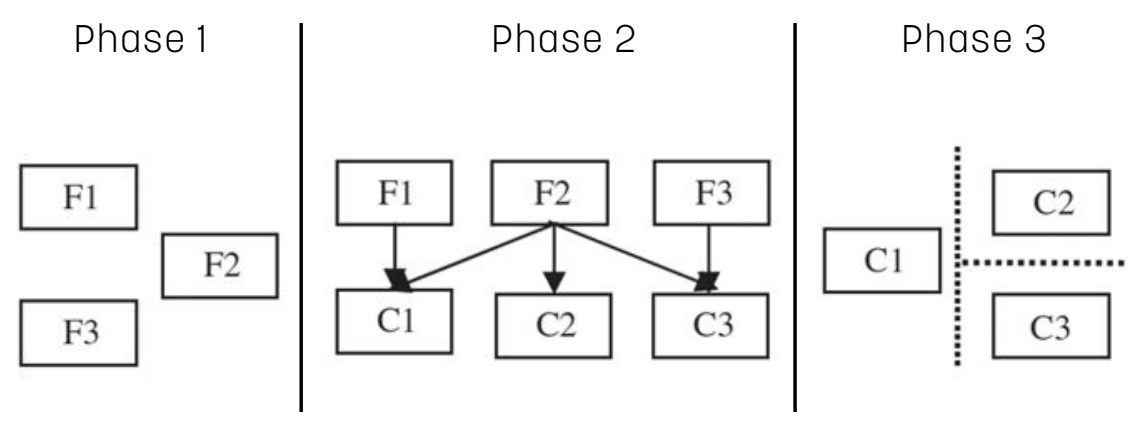

Figure 3. Person छ̊ Åhström's (2006) interpretation of Ulrich's (1995) modularisation process; Phase 1 illustrates arrangement of functional elements, Phase 2 mapping from functional elements to physical components, and phase 3 illustrates the creation of interfaces between physical components. F1-F3 stand for functions and C1-C3 for components.

The decisions on how to divide up a product into modules and determining interfaces between them are made for several reasons ranging from manufacturing and usability to marketing benefits. Ulrich \& Eppinger (2012) give several examples of how to reason when deciding how to create modules:

- Parts of the product need to be upgraded before the product life-cycle ends.

- Parts will be added on to the product.

- The product needs to be adapted to different market needs.

- Parts on the product will wear out before the whole.

- The product has parts that control consumption, e.g. printer cartridges.

- The product has flexibility in use, such as changing of camera lenses.

All of these reasons influence the designer and render possibilities for creating aesthetic variations of a design or adding of new products to a portfolio. 
Redesign means to change an existing product design into a new design. The strategy is usually done to keep up with competitors and trends or make minor changes to brand values; in other words, an "evolutionary" strategy according to Knapferer (2012). Some industries like the auto industry and garment industry have strategic time plans for redesign, extending several years into the future (Solomon, 1988).

Companies utilising branded house strategies in their redesign process need to consider factors such as having a kinship with the company's other products, the design DNA, and competitors' products. Monö (1997, p.146) illustrates the interactions between these factors in the model shown in figure 4. The model shows that when redesigning a product ( $\mathrm{P}$ in figure 4 ) it has to relate to preceding products (the far-left dotted cube), the company's current product portfolio (product range, manufacturer in figure 4), and differentiate itself from competitive products (in the product range square). Monö (1997) states that the reason for this is because: "A product has, metaphorically speaking, a 'social' life that can be described in terms of depth, width and height: its generations in depth (heritage), its family and relatives in width and its competitors in height." Companies with products that have never been designed before do not have a 'social life'. This means that when a designer creates a new design for the first time, they also initiate the company's first design DNA. 


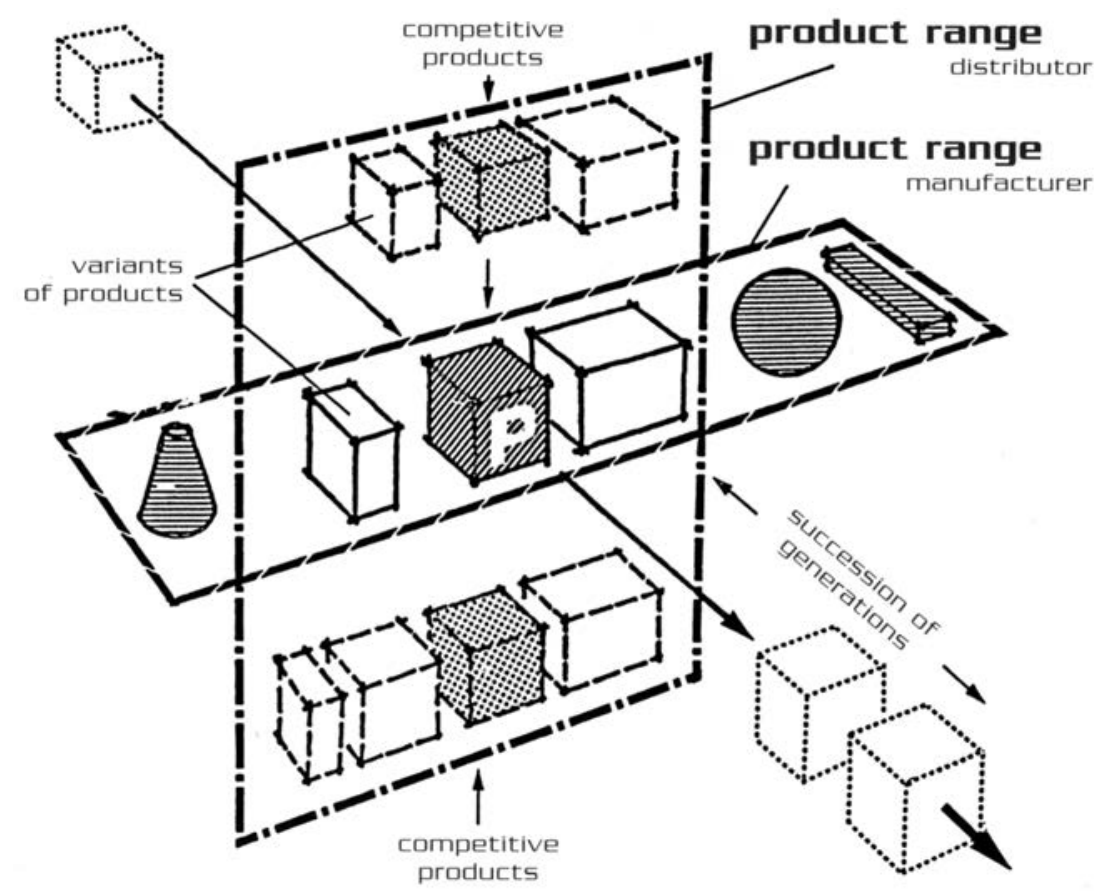

Figure 4. Monö's (1997, p.146) model of "The product sign's relationship to the product range sign".

When the redesign has to be more radical it is called revitalisation by Keller et. al. (2012); it occurs when a brand is regressing due to neglect or for instance bad marketing. A company has then two options; ether to terminate the brand or to do radical changes to both the products and the brand. The main incentive to not terminate a brand is that "...the revitalization of a brand is usually less costly and risky than introducing a new brand, which can cost tens of millions and will more likely fail than succeed." (Aaker 1991, p242). When revitalising branded products the new designs has to be differentiated toward both the company's prior products and the competitors in order to reduce harmful brand associations. 


\subsection{Extension of product brands}

What is seldom described in design literature is that brand extension is a primary strategy for most designers due to the fact that the majority of all product launches are some form of further development (Keller et al., 2012; Kapferer, 2012; Kim \& Mauborgne, 2004). Brand extension is defined by Keller et al. (2014) as "when a firm uses an established brand name to introduce a new product". This means that a designer utilises existing design DNA and design features when creating new products. This is done to benefit from present brand values. Kapferer (2012) and Keller et al. (2012) list some of the most important reasons for brand extensions:

- Give consumers more to choose from and discover other products from the company. This hinders competitors from exploiting a gap in the market.

- Improve the image of the brand. A new extension can add value to an already existing brand line.

- Give consumers quality and trustworthiness in a new product. A new product can use existing brand values instead of having to create new ones.

- Reduce the cost of marketing because the customers have prior knowledge about the product. Marketing only needs to focus on promoting the new product and not a new brand.

- Cost of developing design features is small due to reuse or minor changes. Utilising prior design features aids in brand recognition.

- Efficiencies in packaging and products by reusing components or parts. Lowers development time and can increase visual recognition towards the brand.

Researchers have described at least three product brand extension strategies: Farquhar (1989) classifies two as category extension and line extension and Keller et al. (2012) add a third strategy, called vertical brand extension. 
Category extension is when a company extends its brand into an existing category to compete with other established product brands (Keller et al. 2012). Categories can be constructed by the market through how companies compete, but also by consumer associations. Whan Park et al. (1991) describe consumer associations as both feature similarities between objects (products) and conceptual similarities that may appear to be more or less consistent. When the brand is expanding into a new category, it is critical that there is a thorough understanding of the target category POPs. Conceptual similarity is often constructed from several abstract meanings such as profession, status, high price, compelling design, etc. An example of this is that both Seiko and Rolex belong to the watch category but only Rolex is associated with luxury and high status.

Line extension on the other hand is when a company is expanding within its existing brand line (Keller et al. 2012). Kapferer (2012) lists seven ways to expand a brand line, three of which are relevant for product development. The first is to change the format and size of the products, the second is to create new companion products (shaving cream for razor products), and the last is to extend brand-specific features.

Vertical extension is a version of line extension, but in some respects more similar to Whan Park et al.'s (1991) definition of conceptual similarities in category extension. The company creates "two products from one" by creating a professional, luxury or lowcost version of an existing brand product. One example is Bosch, which created the blue professional series and the green DIY (Do It Yourself) series in order to target different consumer groups and price points (Keller et al., 2012).

For a brand that has a position in the market, brand extension is a strategy to develop a product portfolio and reduce the risk of losing brand recognition. This also means that the three different extension strategies have to be taken into account when expanding a portfolio that consists of modularised products. The choice of strategy will have an impact on in what manner and to what extent the modules should be utilised in new extensions. Differentiation between categories can for instance decrease but the overall brand recognition increase due to repetition of the same modules. 


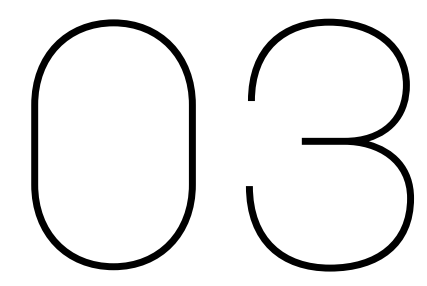

\section{RESEARCH APPROACH}

This chapter describes what research epistemology and scientific methods were used to explore and answer the research questions.

The author's educational background and experience as an industrial designer has been an influencing factor in the choice of research scope in this thesis. Working as a professional industrial designer and simultaneously teaching in design subjects at Swedish universities has created a desire to further understand how skilled designers evolve designs and what influences their aesthetic decisions during the design processes. The exploration of strategic ways of designing products and how this affects the company's product portfolio has been a driving force.

\subsection{Research rationale}

Epistemologically the author has adopted a hermeneutic cyclic approach (Alvesson \& Skjöldberg 2013, p91-94) where the search for comprehension is influenced by the researcher's pre-understanding of the subject matter and the creation of new understandings through literature, interviews with practitioners and a workshop are a part of the knowledge creation. Hermeneutics at its core can be described, as "the meaning of a part can only be understood if it is related to the whole" (quote from Alvesson and Skjöldberg, 2013), 
meaning that the author has had to explore both how the individual in-house designer works (the part) and also how this can influence a company's development of its visual brand appearance (the whole).

\subsection{Overall research approach}

The overall approach in this thesis is qualitative research due to the exploratory nature of the research scope, how the data is collected, and in the way conclusions are drawn (Yin 2014; Baxter \& Jack 2008). The research process is conducted through a series of five different studies, where prior findings generate insights, which then are the base for subsequent studies.

Miles and Huberman's (2014) model of a qualitative data process (figure 5) was used as a framework to collect and analyse information in the conducted studies as well as in the appended papers. It consists of four phases: data collection, data condensation, data display, and conclusion drawing/verifying as can be seen in figure 5. However, different methods and tools are used for each of the phases as will be described in together with the particular study.

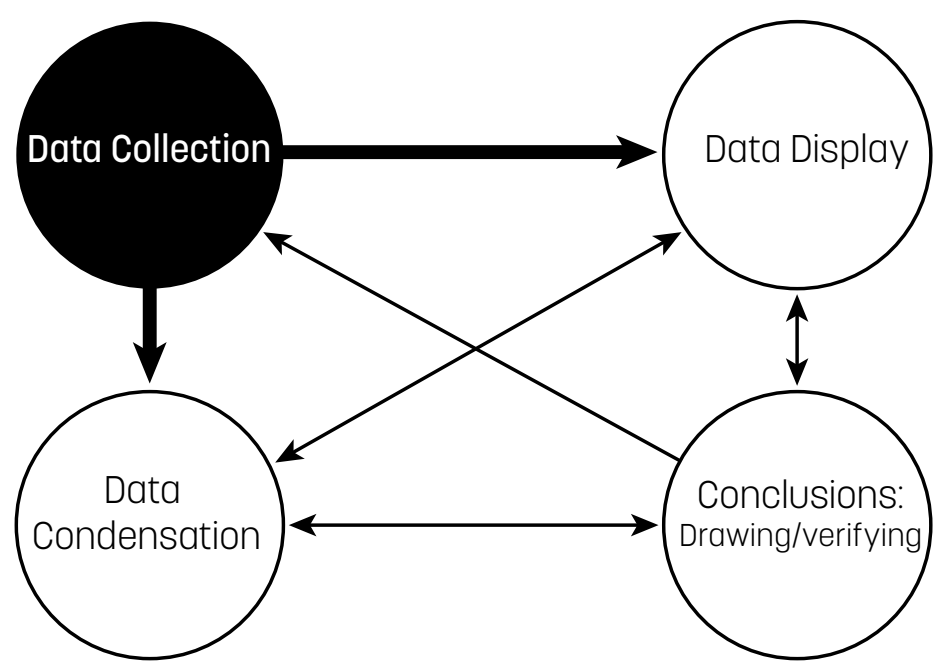

Figure 5. Illustration of Miles $\mathcal{E}$ Huberman's (2014, p14) model for a qualitative data process. 


\section{Data collection}

Data collection involves the gathering of information by different methods and from different sources. Research data is collected from a number of sources, for example academic literature, interviews, design workshops, field notes, design diaries, videos, photos, and sketching materials. Depending on the nature of the study, appropriate methods and tools are used as will be described in later chapters.

\section{Data condensation}

Data condensation is part of the analysis process accomplished by selecting, simplifying and abstracting the collected data. Audiorecorded material was transcribed; coding and searching for themes in the collected material were conducted by searching for verbal references to the work process, aesthetic strategies, brand values and strategically aesthetic decisions. Field notes, design diaries, and the recorded material from the studies were organised and compiled according to how the respondents responded verbally to tasks.

\section{Data display}

Data display is the process of organizing and assembling the collected data. In all the studies, computer software was used to display and organise the data into tables, Power Points and text documents. The studies used 2D-visualisation software to create visual models and visually experiment with conclusions drawn from findings in literature reviews.

\section{Conclusion drawing and verification}

Conclusions are drawn by means of a deductive analyse process where the material is first examined through constructed theories and then 
verified and tested. How the testing and verification is conducted isdescribed in each study. Conclusions from conducted research were used to design research questions and aided in the framing of the research scope. Results from the studies were the foundation for all three of the appended papers. 


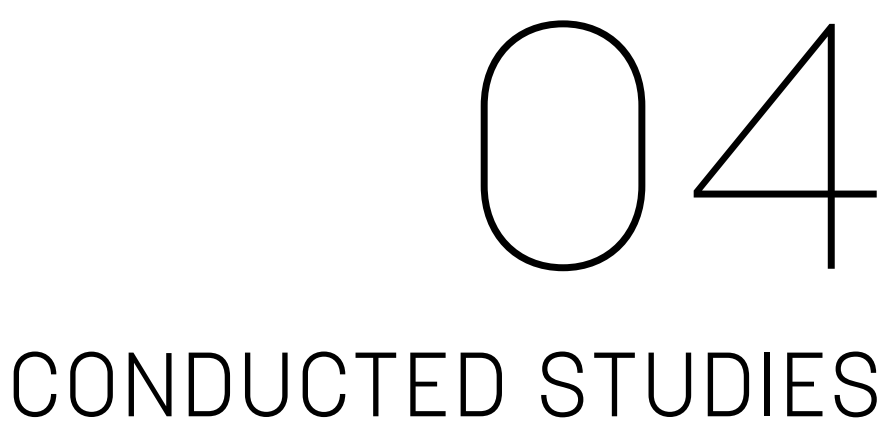

This chapter will present the research conducted through a series of five studies including the rationale behind them, the methods used, and the results obtained. The overall goal was to investigate what aspects can influence designers in their design process.

The conducted studies are presented in a cumulative order where the findings in earlier studies are the basis for research objectives in later studies. Figure 6 shows the order of the conducted studies, what methods where utilised, which papers the studies are associated with, and what research questions they aimed at answering.

The first and second studies were exploratory studies aimed at investigating how designers work when designing products. The investigation in the two first studies was conducted through literature reviews, semi-structured interview, and field notes. From the data theories was built and a method was development. Conclusions from these two studies generated insights, which were further investigated and elaborated in the following three studies and to answer all research questions.

The third study took the form of a design workshop aimed at testing if the key findings from the second study were known to design students. During the workshop students where interviewed, photographed, filmed, field notes where taken, and the respondents filled in a design diary. Conclusions from the study provided insights that where used for answering research question one and two. 


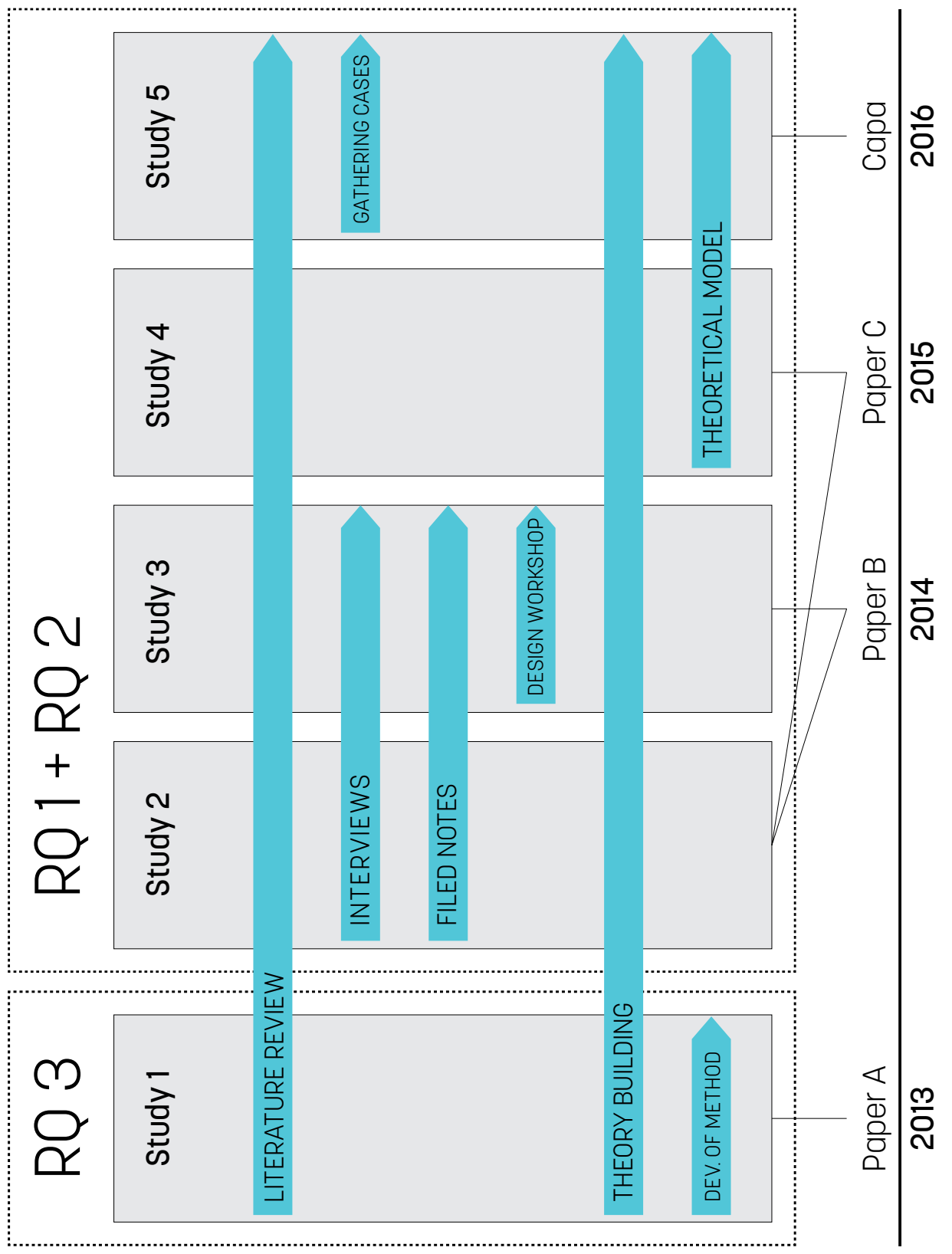

Figure 6. Illustration of how the five studies were conducted as part of this research. The figure also shows how the research questions are linked to the studies and what methods were used in the research process. 
The fourth study built upon findings from study two and a literature review focusing on brand management. The results from study four laid a theoretical foundation for answering all research questions. The theoretical model created in study four and all the key findings from study two were further explored in the fifth study. This was done by searching for products where the findings from studies two and four occurred and then analysing how they might influence a design process, thus answering research question one and two. Each study is presented in detail in this chapter.

The results of study one are also presented in Paper C. Studies two and four are presented in Paper A and study three is presented in Paper B. The fifth study is not presented in any of the appended papers but is a result of a further investigation of a finding from study two. 



\subsection{Study 1 - Product Gist}

This first study was created to explore how competing products influence a new design when a company is expanding into a new category of products and the aim is to create an affinity with that category. When developing this affinity the designer needs to explore what design features create coherence or POP (Point Of Parity) within the category in question. Prior research, conducted by Warell (2001; 2006), Karjalainen \& Snelder (2010), Ranscombe et al. (2012), has investigated and shown how companies develop design features and how these features create visual coherence within a product portfolio but not how the they generate affinity with a product category. Kreuzbauer and Malter (2005) theorise this in their article and investigate how existing category design features can be utilised to expand a product brand into a new category. They don not show how they created or found the existing category features in their article. This will be investigated in this thesis.

\section{OBJECTIVES}

The objective of this study was to explore how design features that are visually associated with a category of products can be found and how this information can be utilised by designers and managers. The aim was to create an analysis method that investigated commonalities in products that was based on these findings.

\section{METHOD}

This study consisted of a literature review, theory building and the elaboration and testing of an analysis method to investigate aspects of category recognition.

A literature review was conducted to get an understanding of the MAYA design strategy, what design features are, and how visual perception influences the creation of recognition as regards a product category. Different data sources have been used, ranging from academic databases and books to Internet search engines like Google pictures. The literature originated from different research fields such as branding, product semiotics, visual perception, product sign, and 
design theory. Conclusions were drawn by comparing what Monö (1997) defines as "the current product sign" * , and literature (Ware, 2008) describing how the brain creates recognition and captures the gist of objects, environments, or creatures.

A theory was formed based upon previous research conducted by Oliva \& Torralba (2006), who illustrate how the brain maps visual information from its surroundings. The theory is that the idea behind their visual examples can be utilised to create an analysis method to investigate commonalities in products, thus finding design features related to a category.

The analysis method was developed by examining pictures made by Dana K (Andersson 2013) and Oliva \& Torralba (2006).

The method of making their pictures was then utilised and the method was tested with product pictures from a mutual single category.

The process of creating the similar picture was documented and analysed, and a generic step-by-step procedure was developed. The proposed procedure is further explained in paper $\mathrm{C}$.

\section{RESULTS}

Results from testing the analysis method suggest that visual information that is related to a product category is detectable and that the information can be subjected to empirical analysis. Figure 7 shows the outcome of the test; it consists of nine side-views of battery-driven power drills. All the products share the same product architecture containing the same modular battery-pack below a handle, with the motor and chuck above the grip.

Four ways of manipulating and overlaying pictures were explored. The first picture in figure 7 used photographs of the power drills; they showed the main shapes, design details, colour schemes and graphics.

* Monö (1997) describes current product sign as: how the market currently perceives a specific product category. 

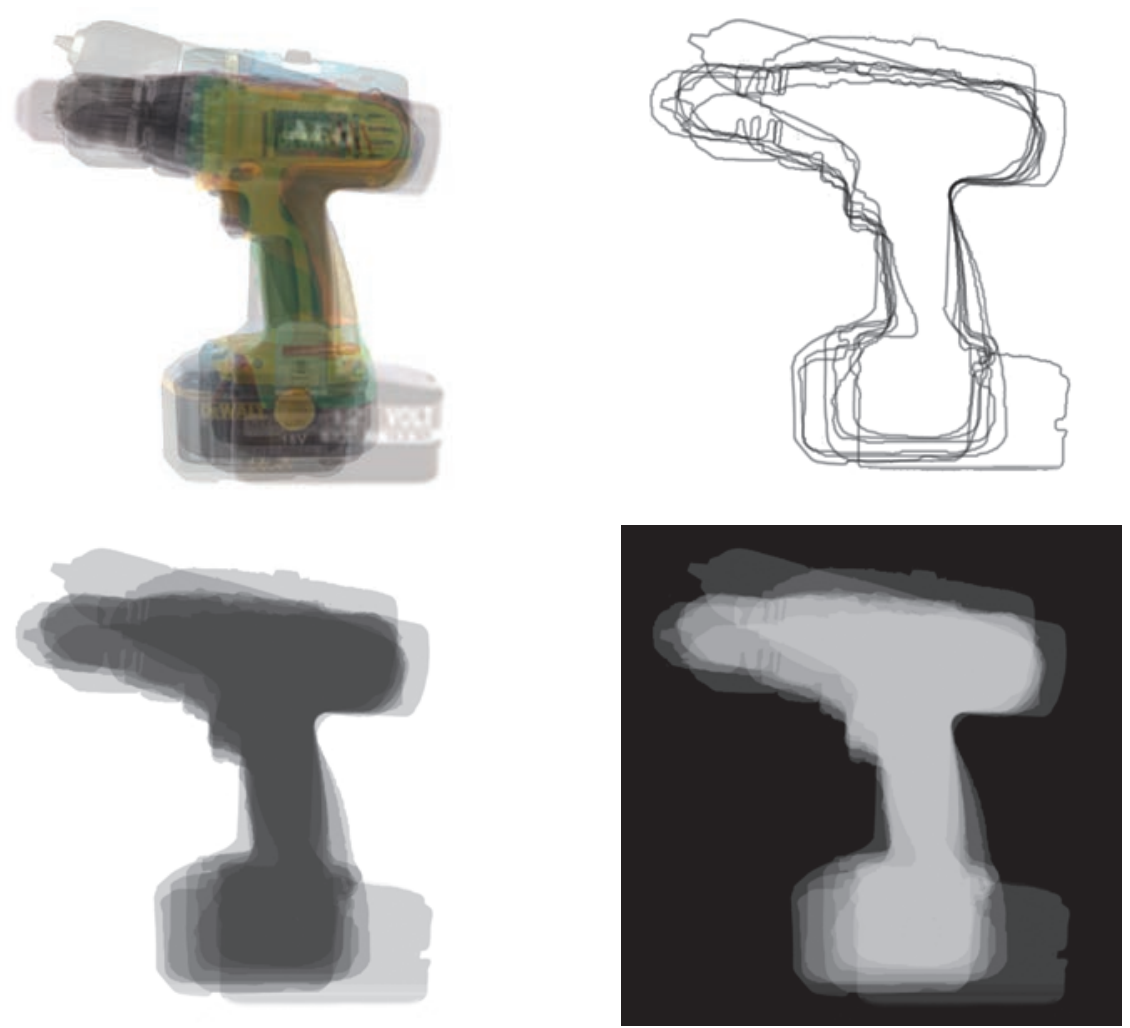

Figure 7. Four overlaid pictures of nine power drills that were outcomes of the test. The first picture shows overlaid opaque photos, the second shows overlaid outlines, and the third and forth show overlaid silhouettes.

The overlaid picture indicated some commonalities in the schemes like dark colour on the battery-pack and chuck. Before overlaying the pictures, their opacity was reduced to make them see-through. The remaining three pictures in figure 7 used the products' outlines to focus on the general form and product layout. The second picture from the left in figure 7 (the line-art picture) is deemed to produce the most explicit visual information of the four pictures. General silhouettes of the current product sign (Monö, 1997) protrude clearly in the second illustration, and at the same time two products distinguish themselves by having a design that stands out from the rest. This shows that the method can also be used to analyse if there are products that distinguish themselves from the total number of investigated products in the selection. 
The new analysis method is named Product Gist. The main contribution of the method is to show how similarities (POP) and differences (POD) can be illustrated in a selected number of products (figure 7), making it possible to empirically study design features in a well-defined product category.

\subsection{Study 2 - Designer interview study}

Results from the literature review and the method test conducted in the first study indicated that designers needed to consider several different form aspects when they create a new design. The prior literature review revealed that important aspects that influence the creation of new forms were: the design history of a company (or design DNA), how the current product portfolio is structured, what design features create coherence within a product category, and how a new design should correlate with the company's existing brand values.

An interview study was set up to investigate how the identified aspects were considered by professional designers and if more design-related aspects could be identified. The study was based upon a theory that the company's development process, product type, and how the product portfolio was assembled would be influencing factors on how designers executed the designs.

\section{OBJECTIVES}

The purpose of Study two was to investigate whether, and if so how, the factors identified in previous studies influenced designers in their work related to the company's development process, product type, and how the product portfolio was assembled.

\section{METHOD}

This study employed a semi-structured interview guide with questions focusing on understanding a company's general product development process, how the company's designers interconnected with the process, and how a specific design process had been performed in 
one of the company's products. Respondents in the study were the chief designer, an engineer, and a surface designer who had been involved in the visual and mechanical design of a chosen product. The company's chief designer had chosen the product. All three respondents were male and had more than five years' work experience in their respective professions. The interviews, which lasted between 60 and 90 minutes, were audio-recorded and later transcribed. In addition to answering interview questions, the respondents were given two types of visual mediating objects containing printed pictures and pen and paper. The material included four printed A4 sheets with photos showing the chosen product from different angles. The pictures were used as a means for the respondents to illustrate their thoughts of prominent design features and the design rationale behind them. In line with recommendations for interview studies, supplementary field notes were taken during the interviews.

The second mediating object consisted of pens and one A3 sheet of paper with a horizontal time-line labelled "project start" at the left endpoint and "project end" at the right endpoint. The time-line was utilised as a means to chronologically map how the respondents interpreted their development process in the design of the chosen product. The collected material was analysed by searching for verbal references to work processes, aesthetic strategies, brand values, design features and strategically aesthetic decisions. The results were displayed as process maps and key findings were the basis for paper B.

\section{RESULTS}

Interview results showed that the designer was involved throughout the whole development process, both as a developer of new designs but also as a supervisor making sure that the designs were followed through in the remaining development process. Results derived from how designs were developed led to the conclusion that the designer utilised, or was inspired by, old design features that were deemed to be a part of the product's heritage. New design features were created and visual coherence as regards both the product portfolio and the product lines were incorporated into the new designs.

A key finding from the study was that the designer used more 
complex design strategies than had previously been described in the literature reviews. The conclusion is that a primary reason for the need for these complex design strategies was how the company's development process was devised. The studied company utilised product modularisation strategies to expand and develop their portfolio. For instance, modules and parts were shared across the portfolio; this affected the design of the products. The interfaces between modules created divisions in the designs, and in some cases modules were given their own unique designs. The divided designs and the designed modules could then be shared across the portfolio or be reused in new products. The study revealed three key findings:

Firstly, designers and product managers decided and planned what modules should be reused from older out-of-date products or reused from existing product lines. This indicated that the designer needed to think about how the reused modules would influence and be incorporated into a new design.

Secondly, designers needed to be visually flexible when creating new designs in such a way as to facilitate partial design changes at a later stage in order to generate quicker design updates without the need to redesign the whole product.

Thirdly, due to the diversity and size of the company's product portfolio some modules were created to be re-used in several different products in order to lower the total number of units.

These findings showed that modular and complex products create the basis for a phenomenon where designers have to consider not only present and future design opportunities but also how to implement a visual design strategy across a portfolio. This phenomenon is called aestheticflexibility* and is defined as: A design strategy considering and allowing for potentialneed for change in future designvariations of the product. The phenomenon formed the basis for paper A and was further developed in studies four and five. 


\subsection{Study 3 - Design Workshop "carry-over"}

The third study was constructed to investigate how some of the findings from study two influenced a redesign process. The focus was on findings showing that the reuse of designed modules in new designs would influence the design process. The idea of the study was to emulate a redesign process where the designer knows from the start that he/she has to reuse a designed module in a future redesign process. The hypothesis was that by doing so the participants would have an opportunity to plan the design during the study, thus enabling strategic design decisions to be studies and traced in the collected data.

A design workshop was organised to further investigate one of the aspects revealed in Study 2, namely how the requirement to reuse existing modules would visually influence the design of a new product. The study explored what strategic design decisions are taken during such a process.

\section{OBJECTIVES}

The study's objective was to investigate how known key finding one and two from study two are; how designers plan and reuse designed parts when they create a new design; and how this would influence a design process. To investigate this, a design workshop was constructed where the main research question was: What aesthetical strategies can be observed in a design process when a participant has to re-use a component (a "carry-over" component)?

* The term aesthetic flexibility was chosen since style flexibility is a recognised concept in leadership and organization development literature. Form flexibility could be a possibility, but was deemed to connect too much with biological chemistry or manufacturing thesauruses. Visual flexibility was also an option but the term was found to be used in research regarding the eye and vision. Aesthetic has a positive connotation and generates associations to values created by designers or artists and flexibility was chosen because it implies both present and future changes in ideas and artefacts. 


\section{METHOD}

The study employed a design workshop methodology (Martin \& Hanning, 2012) with the task to design and redesign a modular product. The workshop consisted of two phases, with a coffee break in-between.

In the fist phase, participants were briefed about the modular product design task. They were also informed that they would have to redesign this product in phase two, and that they had to reuse (or "carry-over") one module from the first phase into the second (redesign) phase. In this workshop the task was to design an electric toothbrush consisting of three modules: toothbrush head, toothbrush handle, and a charging station. Four image-boards filled with pictures of the product category were shown in the first phase so that all participants had the same visual starting point. Participants could choose one of three design modelling media: pen and paper, TecClay (Kolb design technology GmbH \& Co. KG), and CAD (Rhinoceros 3D).

Data was collected through observations, unstructured interviews, photographs, video-recordings and field notes taken during the design workshop. A design diary (Martin \& Hanning 2012; Barapour et. al. 2012) consisting of demographic questions and questions related to the main research question was handed out at the start of the workshop and was filled in by the participants at the beginning of phase one and during the coffee break between phases one and two.

Field notes, design diaries and other recorded material from the workshop was organised and compiled according to how the participants had executed the workshop and how they verbally responded to the workshop task.

\section{RESULTS}

The design workshop was performed by 13 participants, all industrial design master students or PhD students in design. Table 2 shows some of the findings from the workshop. These indicate that while eight participants chose to reuse one part of the design from phase one, five of the participants did not redesign their concept in phase two. They either continued refining their design from phase one or created new designs; in the table these are marked "No Choice". 
More than half of the participants chose the toothbrush head as the carry-over detail and redesigned the toothbrush handle in phase two (figure 8). One participant chose to redesign the button-panel on the toothbrush handle instead of the whole module. Since it was only a part of a module, the concept was marked with an asterisk in the TB-handle column.

\begin{tabular}{|c|c|c|c|c|}
\hline Participant & TB-head & TB-handle & Charging station & No Choice \\
\hline 1 & & $x$ & & \\
\hline 2 & $x$ & & & \\
\hline 3 & & & & $x$ \\
\hline 4 & & & & $x$ \\
\hline 5 & & & & $x$ \\
\hline 6 & & & & $x$ \\
\hline 7 & & $x$ & & \\
\hline 9 & $x$ & & & \\
\hline 10 & $x$ & & & \\
\hline 12 & & & & $x$ \\
\hline 14 & $x$ & & & \\
\hline 16 & & & $x$ & \\
\hline 19 & & $*$ & & \\
\hline
\end{tabular}

Table 2. The table show what modules the participants chose to redesign in phase two of the workshop. TB-head stands for toothbrush head and TB-handle stands for toothbrush handle.

Field notes, photos, and design diaries revealed that there were two main directions of thought among the eight participants who performed the redesign task: unplanned and partial planning. These are described below.

The first direction of thought was to initially not consider the reuse of one part in the second phase. Comments like "I'll deal with that later" or "it's important to let go of the past" were interpreted as a sign that those participants did not plan their designs in order to be reused in phase two. It could also be traced in their design proposals from phase one; the designs had protruding features such as nongeneric major forms with grooves, ridges and spherical shapes on the 
connecting modular surfaces. These were considered to constrain the respondents redesign process by directing them to follow prior designs and narrowing their possibilities expand to more diverse forms.

The second direction of planned design thinking was traced indirectly in the participants' designs. Their designs had less protruding features across the modules and by making surfaces flat, circular, and generically shaped, they had more options to create form variation in phase two.

The study indicated that the understanding of "carry over" is polarised among participants as only eight of thirteen participants fulfilled the workshop as intended and several had no clear strategy for dealing with this challenge in phase two. This finding suggests that most participants had not previously been exposed to the task of partially redesigning a product. A further discussion of the results from the study is presented in paper B.

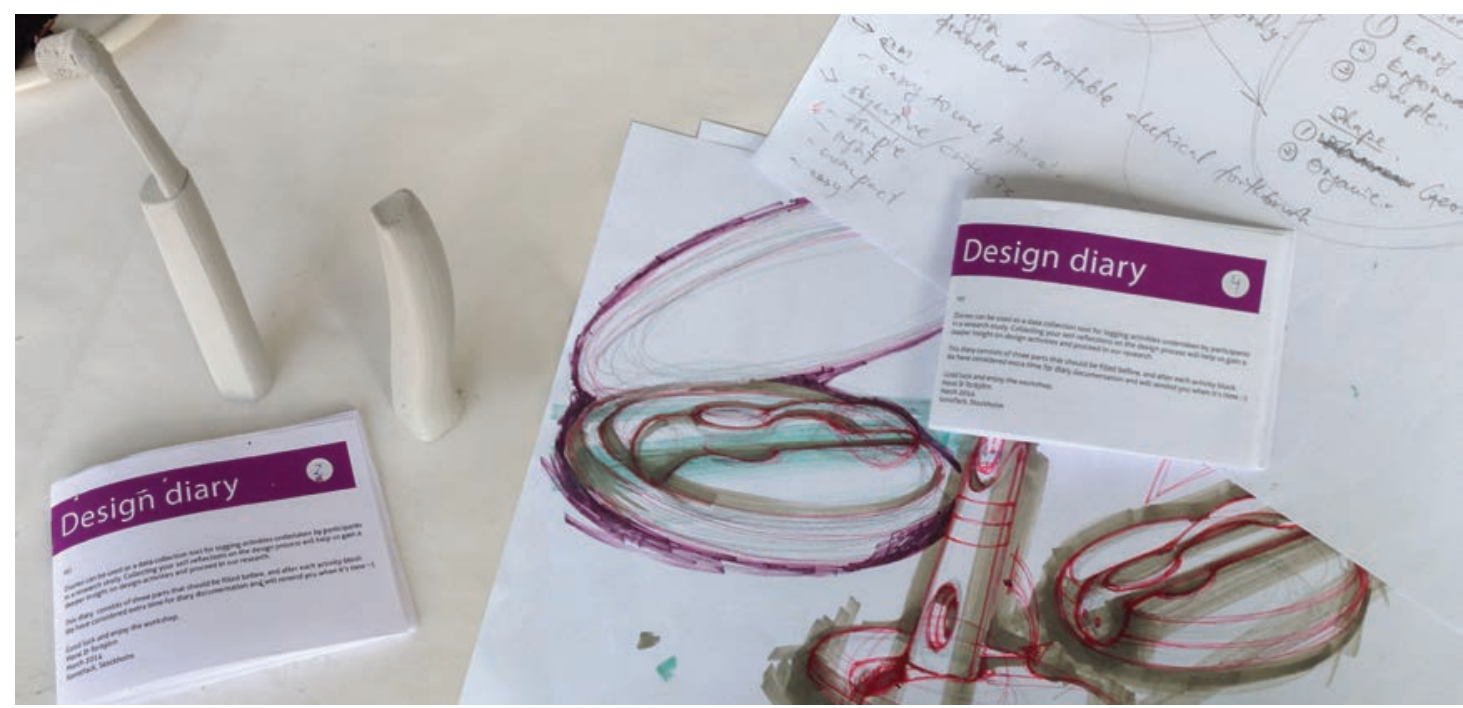

Figure 8. Results from the design workshop. The two pictures show sketches and clay models. The modelling clay is called TecClay and comes from the company Kolb design technology GmbH छ Co. KG. 


\subsection{Study 4 - Brand management's influence on product portfolio development}

From conducted literature reviews, a prevalent idea is that the design of products influences a company's brand value. Some researchers, such as Karjalainen \& Snelder (2010), have even suggested that brand and design features are couple by a bond, meaning that certain design features had to be incorporated in new designs in order to create a connection between the brand and its products. Findings from study two reinforced this idea, suggesting that design features such as colour combinations, specific design lines, and the logo have to be present in all, or the majority of, the company's products in order to maintain the branded house strategy. Consequently, how the brand is managed and developed therefore influences the way a product should be strategically developed.

This fourth study, therefore, investigated what design and product brand development strategies could be found in the literature and how they would influence the development of a product portfolio. This was done in order to understand how these strategies would influence the aesthetic flexibility phenomenon. The reason for this is that when the complexity of products increases and the products are part of a branded portfolio this creates new requirements for the designer.

\section{OBJECTIVES}

The objective of this study is to understand the most common strategies for how an existing product portfolio can be further developed from a design perspective, thereby connecting theories from marketing and brand strategies with industrial design and portfolio development.

\section{METHOD}

The overall layout of this study was a literature review to find product portfolio development strategies and then develop a theoretical model explaining how they are related and interconnected. 
The review focused on product portfolio management and products developed from a design perspective. The data sources used were the academic database Scopus, Google scholar, and books. The literature originated from different research fields such as; brand management and design theory.

Based on conjecture, a theoretical model was developed through a series of 2D-sketches where Monö's (1997) three-dimensional visual model (shown in figure 5) was used as the main source of inspiration. $2 \mathrm{D}$-sketching was used as a method to explore and understand how the strategies identified from the literature review interconnected and how they might influence the development process of new designs.

\section{RESULTS}

From the conducted literature review, five product portfolio development strategies were identified: category extension, line extension, vertical extension, redesign, and revitalization. The strategies were then used to create the Product Portfolio Development model (PPD-model), see figure 9.

In the model the letters A to E represent the five product portfolio development strategies identified: A = Category extension, B = Brand line extension, $\mathrm{C}=$ Redesign, $\mathrm{D}=$ Revitalisation, and $\mathrm{E}=$ Vertical extension. All five strategies are separately exemplified and further developed in the context of aesthetic flexibility, see figure 9 below. The letters $\mathrm{Y}$ and $\mathrm{Z}$ represent a competitor's existing products in its portfolio and the letter $\mathrm{P}$ represents the example company's existing products.

The model consists of a main directional line, starting in the upper left corner and crossing to the lower right corner. The arrow originating from preceding product illustrates that prior products have influenced the creation of the current product [P]. The arrows originating from products $[\mathrm{P}]$ and $[\mathrm{Y}]$ illustrate that when redesigning product $[\mathrm{P}]$ the competitor's product $[\mathrm{Y}]$ will influence the new design concept $[\mathrm{C}]$. The arrow from the cube $[\mathrm{C}]$ towards the sphere [D] illustrates that revitalization has commonalities with redesign strategies but it is a more $\neg$ drastic change in the design, thus 
the different shape to and larger distance from [P]. Perpendicular to the directional line, a plane (the dashed square) illustrates a market where two companies are competing with their product portfolios, i.e. the example company and its competitor. The cubes in the dashed square represent individual products; cubes in a vertical alignment represent a product line. Dashed cubes and spheres represent future products. The dotted arrows aligned to the dashed plane represent influences on and expansion directions of the future products.

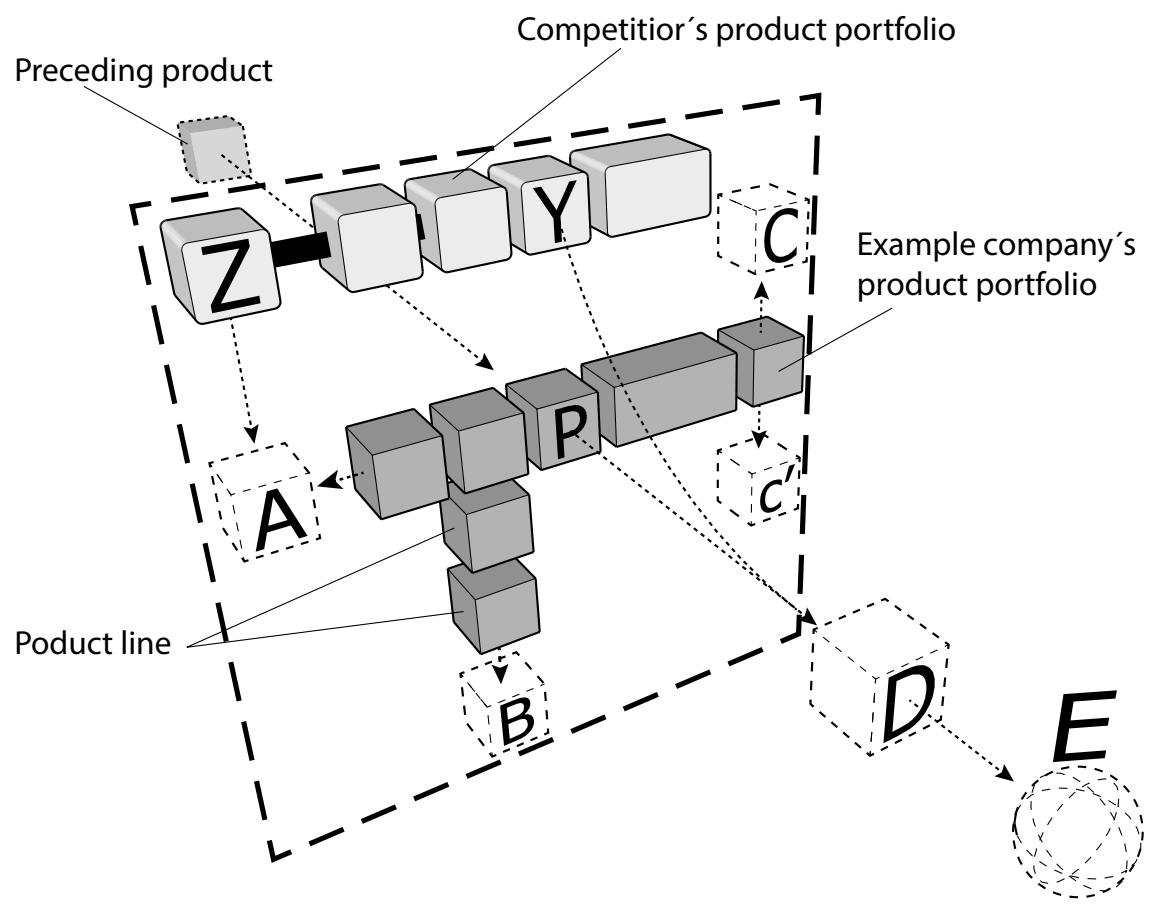

Figure 9. The Product Portfolio Development model (PPD-model) illustrating how expansion and redesign strategies may be utilised in order to expand or change an existing portfolio. 


\section{A - CATEGORY EXTENSION}

Category extension is when a company expands into a new category of products where there already exist competing products [Z] (Keller et al. 2012). The existing products have created shared POPs that link them to the category; these POPs consist of design features that are not connected to a specific company*. The expanding company needs to take existing design features into account and decide how they should be incorporated in the new designs. In a category extension, aesthetic flexibility is accomplished by reusing designed components from the existing product portfolio into the new category designs. Aesthetic flexibility can also be utilised by planning for a future line extensions $[\mathrm{B}]$ in the new product category $[\mathrm{A}]$.

An example is the power-tool producer Makita (se figure 12); they have expanded into the garden-tool category (Makita, 2016), thus starting to compete with other garden-tool producers. This meant that they utilised the category's design features but altered them to be in line with the company's existing design DNA. Garden-tools that are battery-powered incorporated Makita's existing battery solution, thus saving development time and lowering costs.

\section{B - BRAND LINE EXTENSION}

A product line is when products are developed into a series of versions that share one or several commonalities; these can be design features, parts, modules, functions and brand values. Product lines are created to satisfy different customer demands, which may range from functional demands such as more power, add-on products, and product sizes to design variations (Keller et al. 2012). When using the brand line extension strategy [B] on products in a portfolio, aesthetic flexibility is used as a way to create opportunities for cost-effective expansions of the line. By modularizing the line, aesthetic flexibility is used by creating new designs from prior products within the line.

* Study one demonstrates the existence of these shared design features and illustrates how they can be found through the Product Gist method. 
This is done by minor changes to existing parts and modules or variations through, for example, adding a new colour to an existing colour scheme (Klimchuk \& Krasovec 2012).

A resent example of brand line extension comes from the company Husqvarna (Husqvarna, 2016b); they have launched battery-powered chainsaws that extend their traditional product line of petrol-driven chainsaws, see figure 10. The line extension consists of three products where several of the designed parts (handle, bar, buttons and caps) are reused (1); design features from the petrol-driven chainsaws such as proportions, graphics, design lines, material finish, and colour schemes are also reused (2). The battery-pack was reused from other battery-powered products in their product portfolio, creating a visual and functional link between these types of products.

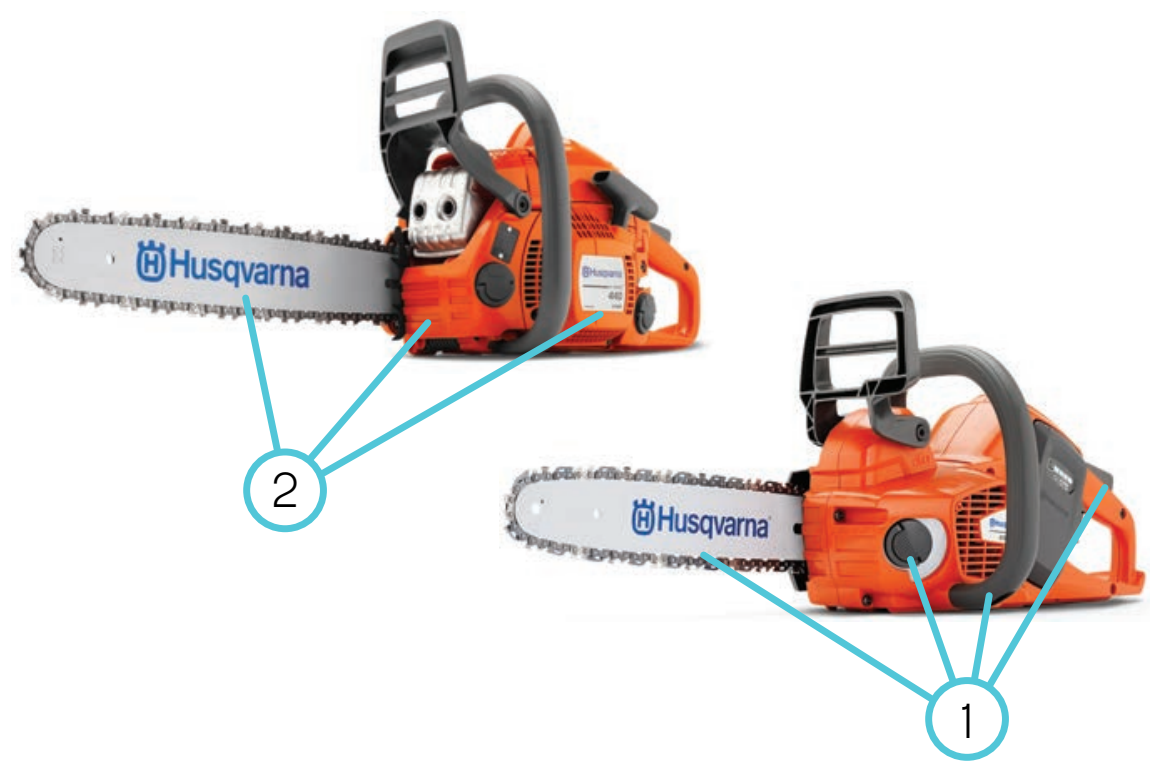

Figure 10. Two versions of Husqvarna chainsaws: the one to the right is a petrol-driven 440 e-series and the one to the left is a battery-powered 436 Li-Battery. Designed parts that are reused in the battery-powered chainsaw are the handle, bar, buttons and corks (1). From the petrol-driven chainsaws, design features (2) such as proportions, graphics, design lines, material finish, and colour schemes are also reused. (Images source: Husqvarna, 2016a) 


\section{C - VERTICAL EXTENSION}

A company that decides to utilise the vertical extension strategy wants to create high-end (luxury) [C] or low-end (DIY*) [c'] products parallel to its existing products (Keller et al. 2012). This means the new designs have to compete not only with competitors but also with the existing products in the current portfolio. Applying aesthetic flexibility on a vertical extension has to be done with care; the extensions need to incorporate POP values that create associations to the desired direction [C]. Designers have to add and remove design features in the existing Design DNA in order to differentiate the new products within the portfolio. From an aesthetic flexibility point-of-view, the sharing of designed modules is precarious due to increased risk of diluting or mixing products' POD values. If it is done successfully it lowers production costs and time to market.

The company Atlas Copco (Atlas Copco, 2016), which produces pneumatic tools, has conducted a vertical extension by creating a pro-range of their handheld pneumatic drills. They differentiated them through an increased feeling of quality, a new colour scheme (1), and minor visual changes to the design (2). This created two visual identities of the same type of product to meet new customer demands, see figure 11.
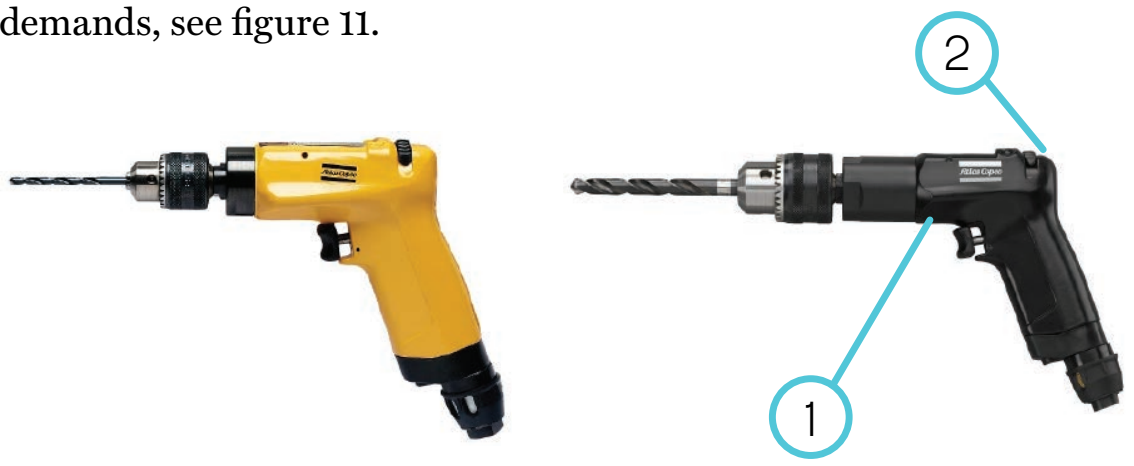

Figure 11. Two versions of Atlas Copco's pneumatic power-drills. The left drill (Combi22) is the regular line and the right drill is from their Pro-line (Pro-D2148). The Pro-line has an increased feeling of quality, a new colour scheme (1), and minor visual changes to the design (2). (Images source: Atlas Copco, 2016)

* DIY stands for Do It Yourself, which can be described as building, modifying or repairing something without the direct aid of experts, e.g. carpenters. (Wikipedia, 2016) 


\section{D - REDESIGN}

Redesign means to change design features and if necessary make minor changes to the brand values of a company's existing product [P] or an entire product portfolio. According to Keller et al. (2012 p731), Ranscombe (2012), and Warell (2008), redesign is a common and evolutionary way to change or update the designs in a product portfolio. It is done to create a feeling of 'newness', differentiate from competitors' products [Y], and change undesired visual associations. In a redesign processes, companies utilises aesthetic flexibility by only redesigning part of a product and reusing parts from other products in the portfolio. In a total redesign, aesthetic flexibility is utilised in order to plan for future design upgrades, redesigns and reuse in other products in the portfolio.

Planned and continuous redesign of products can be seen for instance in Volvo cars, where new car models are presented every other year (Volvo Cars, 2016b). The redesigns in Volvo cars vary from minor colour changes, face-lifts of body-parts, and new interior designs to design changes of entire cars. See the Volvo example in study five (4.5.1 Merged design - Volvo Car Corporation) for more about face-lifts.

\section{E - REVITALISATION}

Revitalisation [E] is a version of redesign [D] but with the difference that it also includes a more profound change to a company's design DNA. The strategy is employed when there is a need to create new positive recognition and a change to the brand (Karjalainen \& Snelder 2010; Kapferer 2012). In a revitalisation process, aesthetic flexibility should be handled with caution due to the risk of moving negative associations into new designs when reusing modules and design features from existing products. Because revitalisation is essentially a redesign process, the same aesthetic flexibility strategy of planning for future redesigns or add-ons can be applied on the new revitalised designs. 
An example of revitalising a company is the British clothing company Burberry. In the 1990s the brand became a favourite of British soccer hooligans. They had been travelling to European cities to see matches and were influenced by the local supporters' branded clothing such as Lacoste, Sergio Tacchini, Fila, etc. The hooligans began to buy or steal these clothes and after a while the more patriotic British supporters started to buy Burberry garments instead. The clothes became a uniform for the "Chavs", as the young hooligans were called, and the bearers were turned away by bouncers and taxis. The negative associations led to a decline of the Burberry Company; the brand was revitalized through repositioning towards high fashion and by discontinuing mass-market products such as their popular cap. They also reduced the use of their check design feature (a camel, red and black coloured check) on the new designs (The Economist, 2011).

To sum up, the PPD-model's contribution is to extend Monö's model (1997), connect it to branding literature, clarify what distinguishes different strategies, and how they relate to each other. This is done by showing how the strategies identified relate to a common product portfolio. A more detailed discussion about the PPD-model can be found in paper $\mathrm{A}$. 


\subsection{Study 5 - Investigating aesthetic flexibility in existing products}

The purpose of study five was to develop and validate the concept of aesthetic flexibility, proposed in study two and investigated in study three, by providing examples of contemporary product design from brands with broad product portfolios.

\section{OBJECTIVES}

The objective of this study is to further theorize the phenomenon of aesthetic flexibility and then exemplify the findings through modular products originating from companies with product portfolios.

\section{METHOD}

The fifth study has a similar structure to the first and fourth studies, starting with a literature review followed by developing theory and then exemplifying the theory with existing product cases.

The literature review focused on strategies and reasons for modularising products in connection with product development. The data sources used were the academic database Scopus, Google scholar, Google pictures, and books. The literature mainly originated from research fields such as product modularity and product development.

The focus of this study's theory building was to further develop the phenomenon of aesthetic flexibility into design strategies. This was done by searching for product examples where aesthetic flexibility was evident, sorting them through the PPD-model and comparing them with product modularity strategies found in the literature review.

The design strategies were then exemplified through product cases. These were chosen by the standards of being global brandedhouse companies and by utilising modularity within their product portfolios. Each product case is chosen to exemplify one of the identified aesthetic flexibility strategies. 
The cases begin with a company and product introductions followed by a description of how they connect to an aesthetic flexibility strategy.

\section{RESULTS}

The theoretical development of the phenomenon of aesthetic flexibility has so far rendered four different types of strategies:

1. Merged design. A module is designed in such a way that its design features merge with design features present in products from other categories or brand lines within the same visual identity.

2. Incorporated design. A module, or part, is created to be an individual unit but has to be part of a product to function. It is designed to be incorporated into different product categories and product lines in a portfolio. The module, or part, has its own design features and visual recognition.

3. Configurable design. A design is divided up in such a way that parts of it can be substituted or modified in order to generate product variations and still maintain the same visual identity.

4. Modular design. Modules or single parts are designed as units with the intention to be utilised to create design variants by repeating the units. The repetition creates aesthetic diversity of a product portfolio without losing recognition toward a company's brand.

Four companies were selected to illustrate each of the strategies: no 1 - merged design with Volvo Car Corporation, no 2 - incorporated design with Makita power tools, no 3 - configurable design with Scania Trucks, and the toy company Lego with no 4-modular design. 
Volvo Car Corporation is a Swedish company established in 1926, nowadays owned by Zheijang Geely HG (Volvo Cars, 2016a). The company produces different types of car models ranging from sedans and coupés to SUVs. The company's visual brand identity is achieved through consistent design formats across all their car models, creating a unified design DNA (or a "Volvo look"). Cars are generally complex and expensive to produce and therefore many car-companies develop their cars in cycles. These cycles are called generations and are several years apart; in-between these cycles minor design changes are made called facelifts. In aesthetic flexibility, a face-lift is the same as the strategy merged design. These facelifts are needed to increase variation over time between generation shifts due to long development cycles, the high cost of changing hard body parts (sheet metal components) and competition in the automotive market (Person M. and Åström P. 2006).

Variation over time, or face-lifts, is achieved through changes in soft body parts (injection-moulded components) and in discrete parts (emblems, mirrors, lighting units, etc.). This can be traced in third generation year models of the $\mathrm{V} 70$ and $\mathrm{XC} 70$, see figure 12 .

Both bumpers on the older versions of the $\mathrm{V} 70$ and $\mathrm{XC} 70$ have been redesigned on the 2014 models, creating a differentiation between year models and feeling of newness for consumers. In the 2014 V70, the most prominent differences can be seen in the design line (1), the grille (2), and the air intake (3). Less visible changes have been made to the 2014 XC70, the most noticeable changes being the design features around the lower headlights (4) and new grooves on the plate that protect the undercarriage (5). 

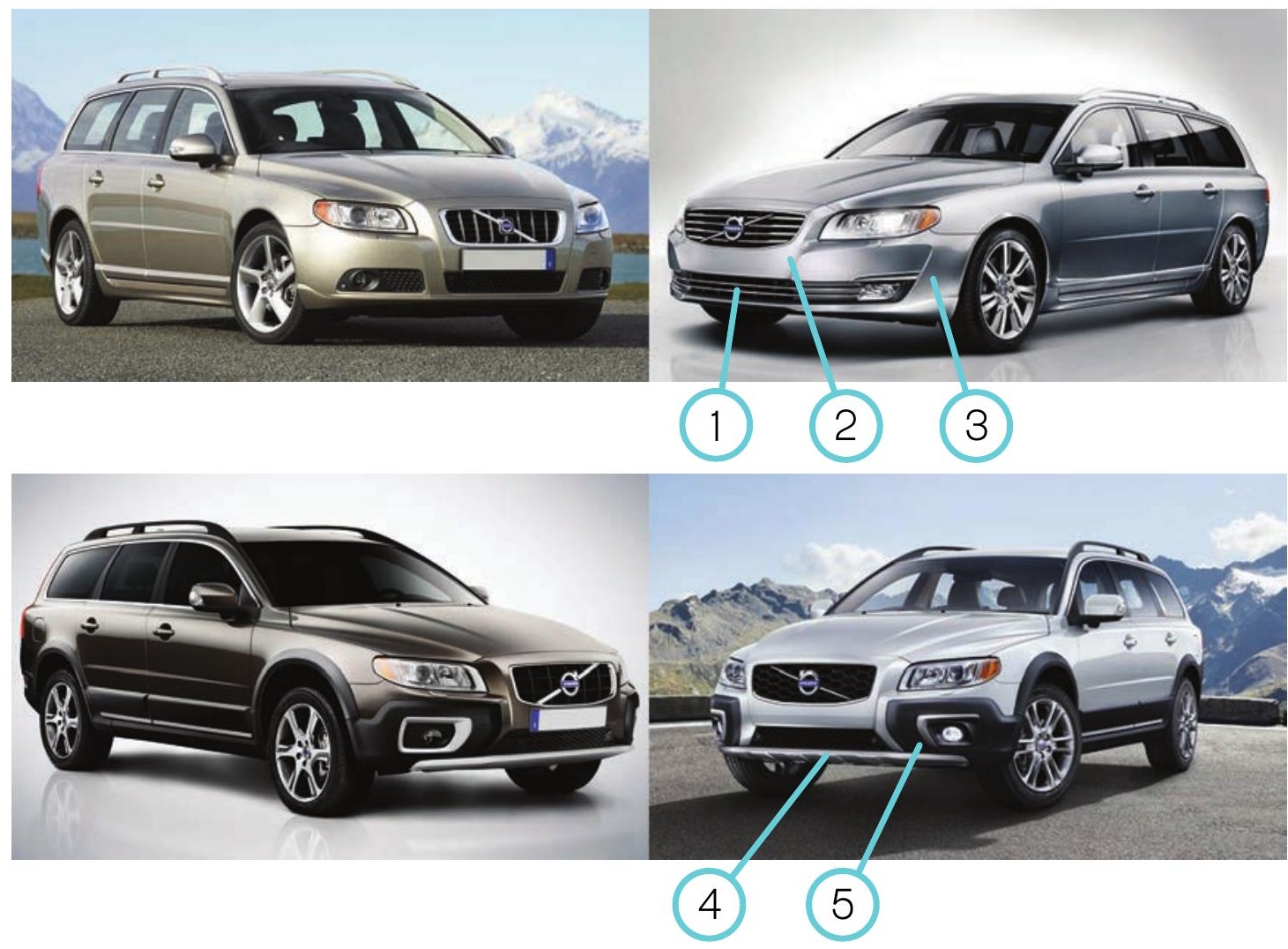

Figure 12. Third generation V7O and XC7O Volvo cars from 2010 and 2014. Facelifts of bumpers can be seen in the 2014 versions. The V7O has the most prominent differences, shown in the air intake (1), the grille (2) and the design line (3). On the XC7O, the most noticeable changes are the grooves on the plate that protects the undercarriage (4) and new design features around the lower headlights (5). (Images source: Volvo Cars, 2016b)

The redesign of the bumpers (figure 13) is an example of the aesthetic flexibility strategy merged design. The facelift of the bumpers has been made in such a way that they do not visually deviate from adjacent body parts, e.g. bonnet, wheelhouse, and headlights. The merged designs is prepared by considering adjoining parts and how they will interact with parts destined for redesign. Examples of this preparation were found indirectly in the third study where respondents who had made their designs more generic and with flatter surfaces, had more options when making varied design proposals. 
The merged design strategy is not only utilised in one car model; they are also applied across categories. This is due to implemented product modularization strategies across all Volvo cars. This is illustrated in figure 13 where the same bumper (1) of the 2014 version of the V7O is used in both the sedan and station wagon versions. This has to be taken into account in the merged design process; the new design has to blend in with adjacent body-parts from both car categories.

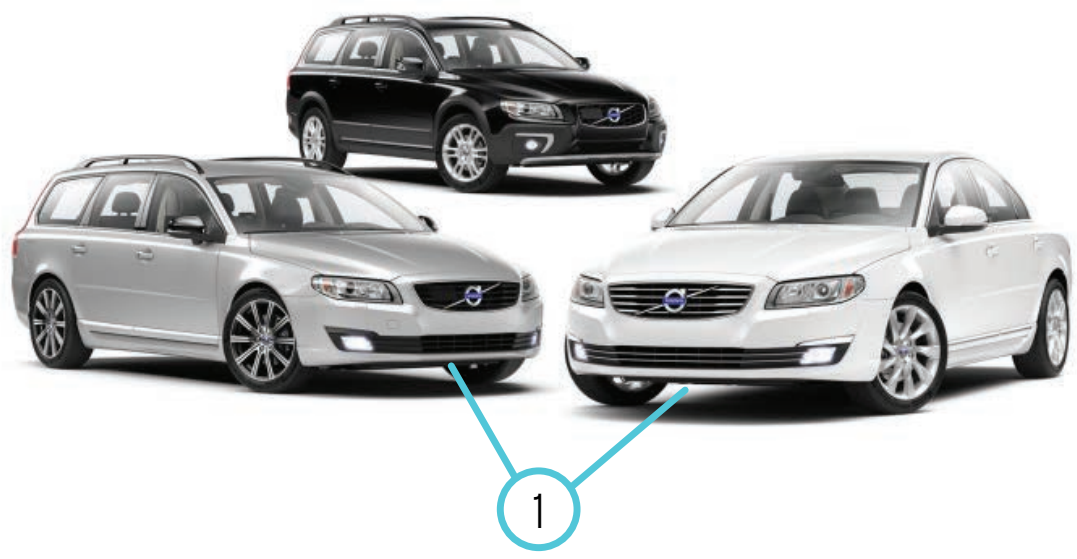

Figure 13. Three different Volvo cars; XC90, V7O, and S60 Cross Country sharing design modules such as bumper (1), rear-view mirrors, roof rails, doors, etc. (Images source: Volvo Cars, 2016b)

Incorporated design - Makita Power Tools

Makita (Makita, 2015) is a renowned power tool company that has developed its portfolio to cover over 100 different products ranging from carpentry tools to electric garden tools. Many of the products in the portfolio use the same battery design, an 18v Lithium-Ion slidestyle battery. The battery-pack module is a stand-alone unit that has its own design features and has been developed in such a way that it can be used in other Makita battery-powered products. The company's product portfolio is divided into categories and product lines (see figure 14). The number of products in the portfolio means that in order to create a consistent design DNA fewer design features 
need to be bearers of the visual brand identity. In Makita's products, the bearers of explicit design features are the colour scheme of black and green-turquoise, the graphics, and repeated design lines, such as those in the handles for example.

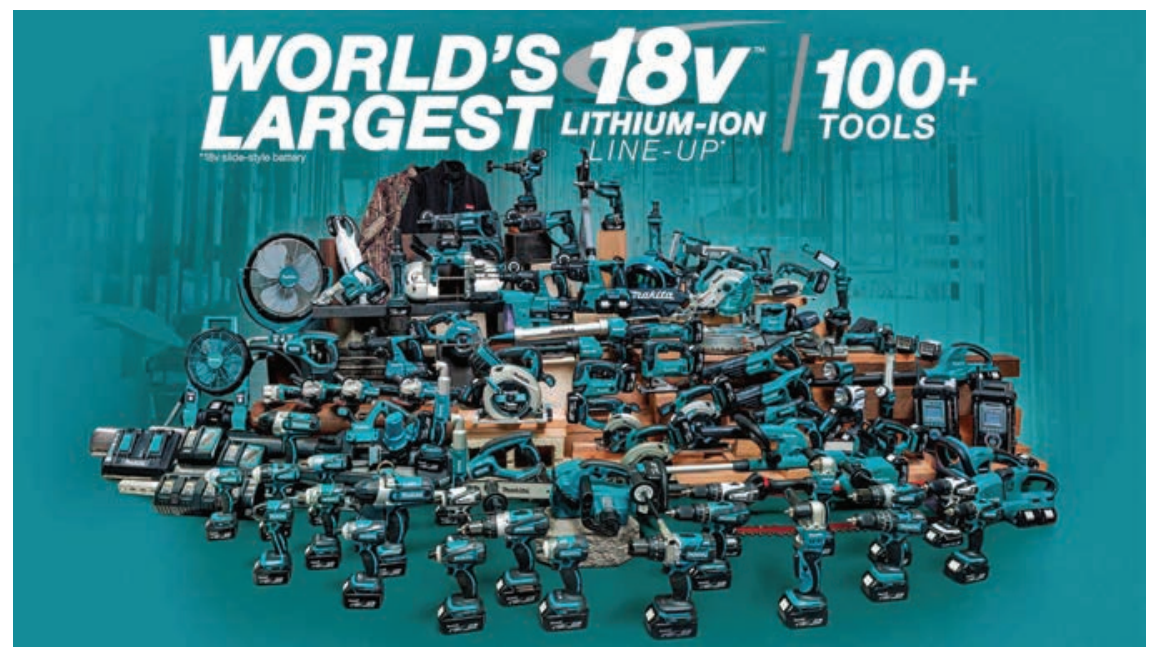

Figure 14. Makita has utilised the incorporated design strategy by using the same $18 \mathrm{v}$ Lithium-ion battery in all of its 100+ tools power tools. (Image source: Makita, 2015)

The incorporated design strategy is present in Makita's products through the reuse of their modular battery-pack throughout their portfolio (figure 14). The strategy of reusing the battery module creates a visual consistency and congruency towards the brand while it also becomes a designed part in its own right. This creates a between-product or portfolio consistency when Makita expands into new product categories or enlarges a brand line. For example, when Makita expanded into the garden-tool category they needed to blend their design lines with category POP design lines that denoted specific garden-tool categories. This was not necessary with the battery-pack's unique design. In that way, the battery-pack supported the development of visual coherence with existing Makita products by repeating the same design features. 
Scania Group is a company producing buses, trucks and engines; they are renowned worldwide for utilising product modularity throughout their product portfolio. The modularisation strategy has made it possible for customers to tailor their trucks by choosing different versions of, for instance, drive-lines, engines, cab sizes, and cab interiors. In this product example, the focus is on how the aesthetic flexibility strategy configurable design can be traced in Scania's truck cabs. Figure 15 shows how the cabs are resized to fit different needs; the larger cabs are used for long journeys with trailers and the smaller cabins are used for shorter daytrips or special vehicles such as garbage trucks. As a product brand strategy, Scania has chosen to create a unified visual identity (or design DNA) instead of having different designs depending on the trucks function (e.g. long journeys vs. garbage trucks). In the PPD-model, this strategy of having the same visual identity in the design is comparable with a brand line strategy rather than a portfolio with different product categories.

Scania's truck cabs are an example of how a company utilises the aesthetic flexibility strategy configurable design. The strategy is achieved through a strategic division of the body-parts; it is done in such a way that variation in cab size can be met without changing the overall design. 


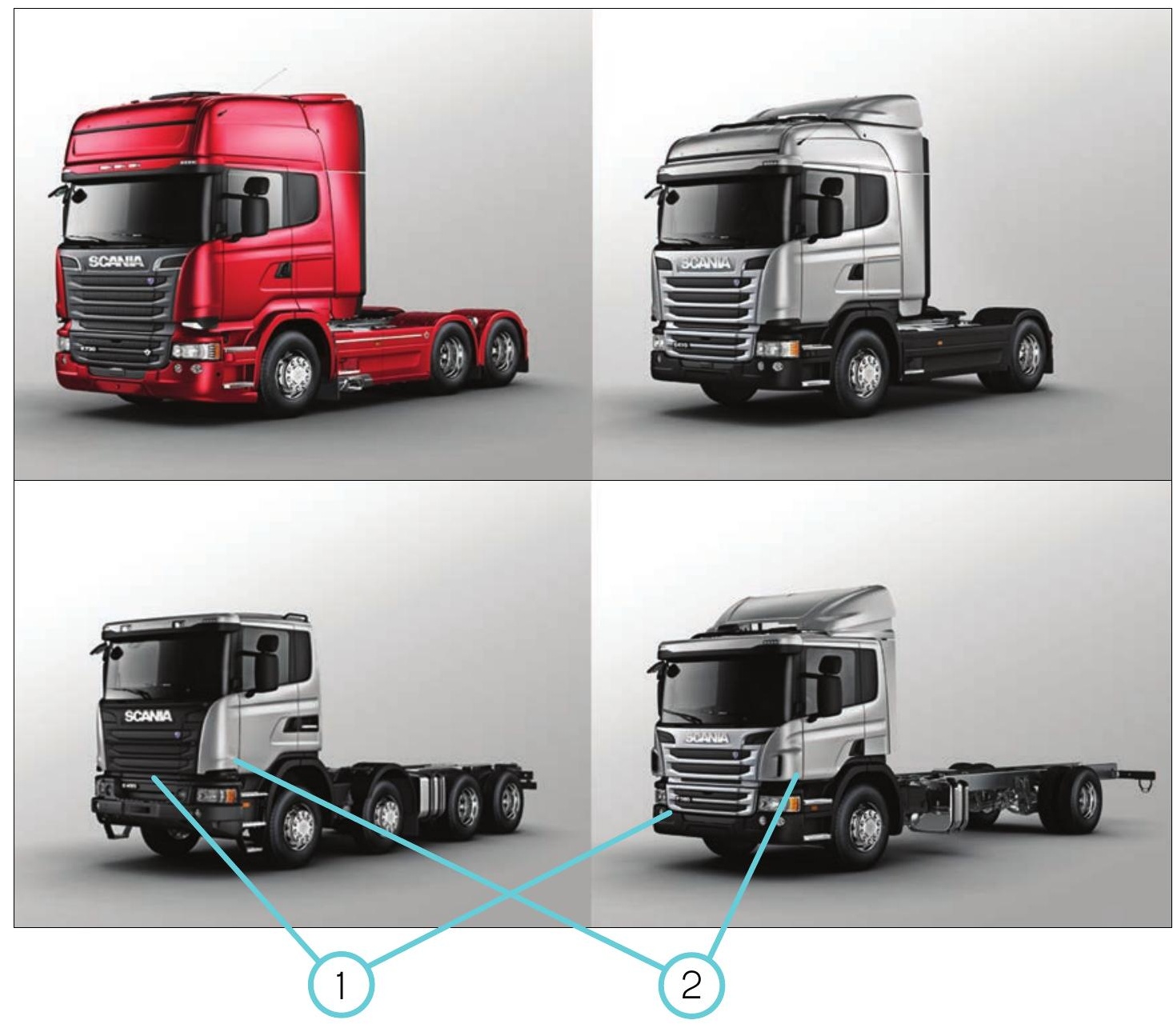

Figure 15. Scania utilises modularity to create five versions by reusing body-parts, yet maintaining the same design DNA. Several body-parts have two or more size variations (1) and contain the same design features (2). (Image source: Scania, 2015)

Several of the body-parts such as the cabin roof (1), the doors, and the side body-parts behind the doors (2) have two or more size variations. Although varying in size the body-parts contain the same design features this makes it possible to make new size versions without losing visual recognition towards the Scania brand. The configurability strategy also allows for redesign of single parts or customer adaptations of body-parts. 
Lego is a world-renowned toy company that has been producing modular plastic bricks since 1949. The word Lego is a union of the two first letters in the Danish words leg godt and can be translated to "play well". Lego produces approximately 9,000 unique pieces per year (including different colours and pad printed versions) and 23 billion pieces in all every year, see figure 16. The company has produced several thousands of different Lego sets since the start with varying themes such as space, robotics, pirates, Minecraft, etc. (Lego, 2016). The large number of unique parts makes it possible to constantly develop new themes and sets with a minimum cost of developing new parts.

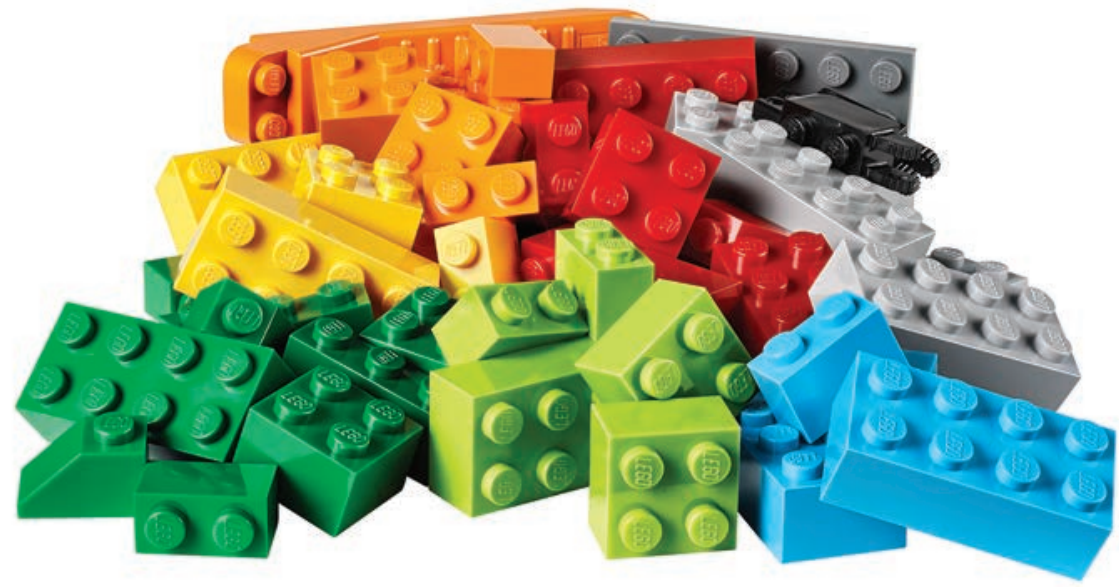

Figure 16. The same Lego bricks in seven different colours (image source: Metro, 2016).

In Lego bricks, the aesthetic flexibility strategy modular design is utilised to the full. All Lego units are more or less compatible with every other unit through a set of constant interfaces and design features. The interfaces make it possible to reuse parts and to create new Lego sets without making new bricks. The interfaces also create a backward compatibility with older bricks and Lego sets. Furthermore, by using the same design features such as geometrical 
design lines, proportionality amongst the bricks, colour scheme, and plastic material, the bricks can be designed and redesigned to match visual themes such as Star Wars, The Hobbit, and Disney Princess without losing the association toward the Lego brand. This shows that aesthetic flexibility is utilised in the design of new Lego sets and bricks.

To conclude, all four product cases demonstrate that aesthetic flexibility is a planed strategy where the involved products and portfolios has been prepared to be altered. In all of the cases, the products had undergone a modularisation process where interfaces between parts, modules, and functions were determined. The cases also demonstrated that companies with a goal to achieve consistent visual identity have much to gain from using aesthetic flexibility. This is because the exemplified strategies make it easier to reuse the same designs across products in a portfolio by repeating the same design features. 


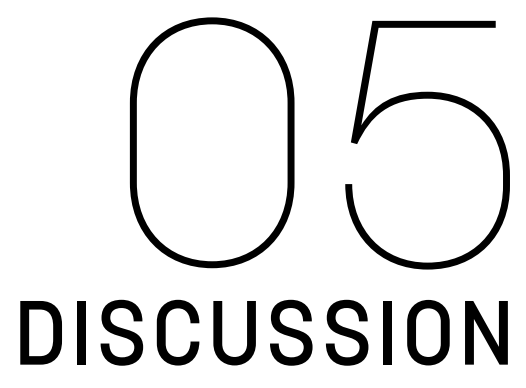

In this chapter the results from the conducted studies, the research approach, and the limitations of the research are discussed.

The thesis demonstrates that advances in fields such as product management and brand management have over the years led to development of more complex aesthetic design strategies in, for instance, the high-tech and automotive product segments. The need for these strategies arises when companies are exposed to market competition and thus need to utilise product modularity strategies when redesigning and expanding their product portfolios. Some of the main reasons described by Ulrich and Eppinger (2012) for companies to employ this strategy are to be able to manage large numbers of units and parts, reduce costs, shorten time-to-market, and make product customisations.

\subsection{Aesthetic flexibility and its influence on designers' thinking}

This thesis has identified and described a design phenomenon, which has been termed aesthetic flexibility, and has tried to illustrate how designers manage this complex design situation. Because of the conditions that determine the occurrence of the phenomena, designers have had to alter their way of thinking. Designers have to consider 
both the present design-task and how it can influence or create conditions for future design updates that are not yet imagined. In addition to this, when product modularity (Ulrich, 1995) is combined with the branded-house strategy (Kapferer, 2012) it creates an incentive to share designed parts between products in the portfolio. This can be described as "lateral" strategic thinking in the design process. The lateral thinking manifested itself through the need to consider how new designs create a unique visual recognition in a portfolio and how parts of the new design can be incorporated into existing product categories and product lines.

Study five demonstrates how four companies (Volvo, Makita, Scania, and Lego) have utilised both lateral and future design thinking in their product portfolios, thus validating the fact that aesthetic flexibility is present in today's products. The four product cases show that a lateral way of thinking is present when modules such as a battery-unit (figure 14) are shared across a portfolio and influence new designs in both category and line extensions. Future design updates are demonstrated by looking back on older versions of a Volvo car model (figure 12) and being able to track the redesigns, or face-lifts, that had been made of bumpers and not of expensive metal bodyparts.

The implication of the phenomenon of aesthetic flexibility is significant, as it shows that product and brand management strategies have a great impact on how professional designers think. Furthermore, it has been shown how it alters their design process. The term and definition can be used to broaden the understanding of what professional designers have to take into account when developing new visual appearances. From an academic point-of-view, aesthetic flexibility can be used to diversify research approaches in design and develop new methods and tools. The four aesthetic flexibility strategies, which are described in study five, are a first step towards developing the phenomenon into design strategies, but are also a means to map aesthetic flexibility in existing products. Using the strategies, new ways of managing and developing a product portfolio from a design perspective can be explored. 


\subsection{Aesthetic flexibility's influence on a design process}

The conducted research demonstrates the fact that aesthetic flexibility is best suited for planned incremental development processes of products where a congruent design is the goal. These conditions make it possible to repeat not only design features but also reuse designed modules, thus decreasing development time, lowering costs and enabling gradual variation. It also gives an opportunity to redesign a product where it gives the most effect, meaning that if a product is divided up redesigning can be conducted on parts that are deemed to be more important for the creation of product identity rather than the whole product. This allows for increased design consistency over time, thus reducing the loss of visual brand recognition.

According to Diffner (2011), there are drawbacks with this strategy. If a module breaks or a product falls into disrepute (as with the Burberry example described in study four), this influences the rest of the portfolio and increases the risk of damaging the brand. Consequently, this will render larger costs for redesign or even increase the need for revitalisation of a brand. This makes it important for designers and managers to have an understanding of when to incorporate aesthetic flexibility and when not to.

The challenge for designers therefore lies in creating enough aesthetic flexibility in designs to benefit from modularisation strategies, but not so much that it create lock-in effects and thus hinders development of new designs. 


\subsection{The influence of brand extension and redesign strategies on aesthetic flexibility}

Study four presents the PPD model (Figure 9), which describes the relationship between brand, design strategies, and their influence on a product portfolio. The model was developed based on findings in design and branding literature, which suggested that the design of products is a main source of creating brand identity and that a brand can be developed by altering the product design (Keller 2012, p 208; Knapferer 2012; Karjalainen \& Snelder 2010). In addition to proposing a model of how brand extension and redesign strategies are connected, the PPD model also describes in what way aesthetic flexibility can be utilised in the different portfolio development strategies.

The impact of the PPD model in academia is that it shows how fundamental aspects of product brand development are connected, thus furthering the current understanding of the connection between brand management and product design. The PPD model will also be useful as a tool for academics, teachers and professionals for understanding different ways of developing a product portfolio, while simultaneously best utilizing the phenomenon of aesthetic flexibility.

\subsection{Product gist and aesthetic flexibility}

The study of a product's gist shows that understanding what generates visual coherence within a category of products is essential when expanding an existing product portfolio into a new category of products (Keller 2012, p 208; Knapferer 2012; Monö 1997). This means that finding the gist of a product category, i.e. category POP, is an important step when expanding a portfolio. This knowledge will aid the designer when creating new deigns that utilise aesthetic flexibility. The defined Product Gist can show how design features need to be adapted to create coherence towards competing products, in order to be associated to the category, and assist in determining 
what modules and parts are to be carried over from other products in the portfolio. This is illustrated in the Makita example in study five, where not only the battery-pack and buttons have been reused, but also other parts such as handles (figure 7); these, however, have been modified to fit the new product category and are thus not a genuine carry-over part but a redesigned part that does not deviate from a defined design DNA.

Results indicate that Product Gist can be used to empirically explore a category of products in order to find visual commonalties, but also to reveal design features that are unique to a specific product or visual brand. In the study, two electric power-drill outlines revealed salient features that were characteristically different from the remaining seven; one being slightly shorter and thicker on the top "motor-part" (above the handle), while the other had a different angle between the handle and the top "motor-part", figure 7. These two products were from two known brands: Makita and Ryobi, respectively. Although tentative, a test of the method shows that empirical results can be obtained and that the method assists both designers and brand managers. The results show that the method can be utilised when exploring how to broaden a product portfolio by expanding into new product categories and how to utilise aesthetic flexibility in it.

It is anticipated that the method may also be useful for design teaching, in that it can aid design students in understanding the balance between creating a new design and creating coherence towards a product category and a branded portfolio.

\subsection{Reflection on the research approach}

This thesis has taken an exploratory approach where the author's own experiences in the design field have had an impact on the research direction. The main reason for this approach was the need to both understand the field of design research and explore possible research goals. The exploration has lead to cumulative findings where 
discoveries in the earlier studies have formed the basis for research objectives in the later studies. This research approach has made it possible to investigate and further develop the phenomenon, ideas, and theories in a structured manner.

The qualitative data process by Miles and Huberman (2014) was a useful framework in the conducted research, as it aided the research process by creating an outline for the studies and their method of qualitative data analysis and when exploring the text-based data. While rendering a broader variety of insights, the exploratory research approach has been a time-consuming process when examining the data.

The company in study two had gone through an extensive redesign process throughout their entire product portfolio, which provided a rich source of data for the interview study. The complexity and size of their product portfolio and the nature of their products (high-tech) provided insights into the use of strategic thinking for carry-over and face-lift design. These discoveries were further investigated in studies three to five. Study two also showed that combining interview techniques and visual aids was a good way to involve the respondents in the research topic and get an understanding of the respondents' reflections on their design and development work.

Designing and executing a workshop (study three) was a good experience in gathering implicit and tacit knowledge of actual performance of a design task, or what Schön (1987) calls doing-in-action. Taking photographs, filling in design diaries, taking field notes, and observing were useful methods for collecting data during the design workshop.

The research conducted as part of this thesis suggests the potential of this field of design research. However, further studies need to be conducted in order to deepen, verify and validate the results. The number of respondents was also rather small in the conducted studies. For further research, the aim is to continue to study the phenomenon and develop it by interviewing more respondents and 
discussing it with other researchers in the fields of design research, brand management and product modularity.

\subsection{Limitations}

This research took an exploratory approach in the conducted research studies; the most limits are thus connected to the need for further studies in order to validate and confirm the findings. The validation needs to be conducted by professional designers who are familiar with working with branded and modular products.

The first study considering the product gist method was only preformed on one homogenous product category and no comparisons were made between categories. Hence, the method is a postulation that requires validation through further studies. Its usefulness could also be assessed by letting trained designers use the method.

In the second study, the interviews were only conducted at one company where the focus was on the design function in the company, limiting conclusions about other influencing factors of a product design process. The results show that it was the right type of company and respondents. Conducting more interviews at additional companies, however, would naturally have given even more insights.

The design workshop, study three, was performed with industrial design students and students in design research and not with experienced industrial designers. Their lack of professional experience limits conclusion drawing regarding the carry-over strategy, which was found in a professional setting, study two. The number of participants was also too high to do in-depth observation studies in the workshop; it became difficult to follow all participants' individual aesthetic choices, thus making it challenging to find and track their design progress. 
The PPD-model, developed in the fourth study, has been published but not tested or validated by professional designers and brand managers. It is also limited to only encompass how an existing brand can be developed and not new brands or categories where there are no precursor products. This is a natural direction for further research.

The product cases in study five were selected to illustrate the four identified aesthetic flexibility strategies, but these need to be verified through interviews with managers and designers in order to validate the conclusions drawn. Furthermore, additional companies and products should be considered to further explain and investigate the proposed aesthetic flexibility strategies. 


\section{6 \\ CONCLUSIONS AND FUTURE WORK}

This chapter answers the research questions stated at the beginning of the thesis and presents directions for further research.

RQ 1:

What design strategies are employed when redesigning/upgrading a modular product portfolio?

The research has identified a phenomenon denoted aesthetic flexibility that describes aesthetic considerations when redesigning a product portfolio. The phenomenon has been described and connected to the proposed PPD-model. Furthermore, based on aesthetic flexibility, four strategies have been identified that could be utilised when redesigning a modular product portfolio: merged design - as a way to plan for future design updates; incorporated design - to strategically design a module to be distributed across a portfolio; configurable design - to divide up a design so that it can be altered to new demands: modular design - which is used to create designed modules that can be repeated or varied in order to produce aesthetic diversity. 
RQ 2:

How can the process, redesigning of modular products, be connected to existing brand extension strategies?

The research conducted has resulted in the PPD-model that can be used to map branding and design strategies that are associated with the development of product portfolios. The model describes how aesthetic flexibility can be utilised in different ways by industrial designers, depending on if a product portfolio is extended or redesigned. On a general level, the research concludes that product modularity and brand extension of branded house portfolios use the same main idea. Both strategies aim at expanding a portfolio with as few means and resources as possible.

\section{RQ 3:}

How can the visual characteristics of a product category be identified and used as a support for product categorisation?

The proposed method, called Product Gist, was explored and empirically investigated in order to reveal visual characteristics of a product category. Results indicate that it is feasible to gain visual insights about category congruencies in homogenous product categories. Specifically, the method helps in exploring design features that aid quick recognition or capture the "gist" of a category. The method is also helpful for understanding variety in visual expression within a category and to identify salient design features. 


\subsection{FUTURE WORK}

Aesthetic Flexibility is a newly discovered phenomenon that occurs in professional design settings where the modularity of products plays an essential role. The plan for future studies is to further explore the phenomenon of aesthetic flexibility, for example through:

1. Further interviews and case studies with in-house designers working in different types of product companies that have strong brands, complex products or large product families.

2. Design workshops where the phenomenon is tested on practicing designers and design students.

3. The four aesthetic flexibility strategies need to be further investigated and verified by both professionals and academics.

4. Development and testing of one or two tools that can aid industrial designers when utilising AF in their work.

A second objective is to further develop the PPD-model to include more aspects of how to develop a product portfolio. For example, when there are no category predecessors or when products have to diverge from each other in a portfolio. The presented model has been peer-reviewed in a journal but not widely spread in academic design research or validated by professional designers or product and brand managers. This is also a direction for further research.

Finally, the Product Gist method could be further investigated and employed on more product categories, and its usefulness could be evaluated by studies on professional designers or in teaching activities. Hence, its usefulness together with aesthetic flexibility and the PDP-model will be further explored. 



\section{7 \\ REFERENCES}

Atlas Copco, 2016. Handheld pneumatic drill. [image online] Available at: $<$ http://www.atlascopco.se/sesv/products/bearbetandeverktyg/1528352/ > [Accessed 03 May 2016]

Barapour, M., Rehammar, B., and Rahe, U., 2012. A comparison of Diary Method Variations for Enlightening Form Generation in the Design Process. DRS 2012, Bangkok Chulalongkorn University Bangkok, Thailand, 1-4 July 2012

Baxter, P. and Jack, S., 2008. Qualitative Case Study Methodology: Study Design and Implementation for Novice Researchers. The Qualitative Report, vol.13, Issue 4, p.544-559.

Buchanan, R., 2001. Deign Research and the New Learning. Design Issues, Volume 17, Issue 4.

Chandler, D., 2007. Semiotics the Basics. 2ed. Routledge, London and New York

C. Whan Park, Milberg, S., Lawson, R., 1991. Evaluation of Brand Extensions: The Role of Product Feature Similarity and Brand Concept Consistency. Journal of Consumer Research, vol. 18, Sept., p.185-193.

Davis M.L., 1987. Visual design in Dress. Engelwood Cliffs, NJ: Prentice-Hall. 
Diffner B., 2011. Combining Flexibility and Efficiency in Automotive Assembly - Preparing for New Powertrain Vehicles. Licentiate thesis, Linköpings University, Linköping Sweden

Farquhar, P.H., 1989. Managing brand equity. Marketing Research, Sep89, Vol. 1 Issue 3, p.24-33.

Goode M.R., Dahl D.W., and Moreau C.P., 2013. Innovation Aesthetics: The Relationship between Category Cues, Categorization Certainty, and Newness Perceptions. Journal of Product Innovation Management, Volume 30, Issue 2, p.192-208.

Hekkert P., 2006. Design Aesthetics: Principles of Pleasure in Design. Psychology Science, Volume 48, p.157-172

Hollins B., and Pugh S., 1990. Successful Product Design. London: Butterworths.

Husqvarna, 2016a. Chainsaws. [image online] Available at: <http:// www.husqvarna.com/se/products/chainsaws/136-li-batteri/> [Accessed 26 April 2016]

Husqvarna, 2016b. Consumer brands. [online] Available at: <http:// www.husqvarnagroup.com/sv/verksamheten/consumer-brands> [Accessed 21 February 2016]

Kapferer, J-N., 2012. The new strategic Brand Management: Advanced insights $\mathcal{F}^{\circ}$ strategic Thinking, 5ed. Croydon, United Kingdom.

Karjalainen M., and Snelders D., 2010. Design Visual Recognition for the Brand. Journal of Product Innovation Management, Volume 27 , p. $6-22$

Kellaris, J.J., and Kent, R.J., 1993. Exploring Responses Elicited by Music Varying in Tempo, Tonality, and Texture. Journal of Consumer Psychology, Volume 2, Issue 4, p.381-401. 
Keller, K.L., Aperia, T., and Georgson, M., 2012. Strategic Brand Management: A European Perspective. 2ed.

Klimchuk, M.R., and Krasovec, S.A., 2012. Packaging Design: Successful Product Branding from Concept to Shelf. 2ed. John Wiley \& Sons, Inc., Hoboken, New Jersey

Kippendorf, K., 1989. On the essential context of artefacts or on the proposition that "design is making sense (of things)". Design Issues, Volume 5, Issue 2, p.9-39.

Kotler, P., 2003. Marketing management. 11th ed. Upper Saddle River, New Jersey, Prentice-Hall.

Kreuzbauer, R., and Malter, J.A., 2005. Embodied Cognition and new product Design: Changing product form to influence Brand Categorization. Journal of Product Innovation Management, Volume 22, Issue 1, p.65-176.

Kreuzbauer, R., and Malter, J.A., 2007. Product Design Perception and Brand Categorization. Advances in Consumer Research. Volume 34, p.240-246.

Lego Corporation, 2016. Making Lego bricks [online] Available at: $<$ https://education.lego.com/en-au/about-us/lego-educationworldwide/making-lego-bricks> [Accessed 22 April 2016]

Lehu, JM., 2006. Brand Rejuvenation: How to protect, strengthen and add value to your brand to prevent it from ageing. Kogan Page, United Kingdom, London.

Lewalski, ZM., 1988. Product Esthetics: An Interpretation for Designers. Design \& Development engineering Press. Carson City, NV.

Lowey, R., 1988. Industrial Design. 2ed, London: Fourth Estate Ltd. 
Makita, 2015.100+ Makita tools. [image online] Available at: <http:// makitatools.com/en-us/Modules/Tools/LXTBrushless/toolcount. aspx $>$ [Accessed 25 November 2015]

Martin, B., and Hanning, B., 2012. Universal Methods of design. Rockport Publishers, China.

Metro, 2016. 10 greatest individual Lego bricks ever made. [image online] Available at: <http://metro.co.uk/2014/02/14/ the-lego-movie-the-10-greatest-individual-lego-bricks-evermade-4299533/> [Accessed 17 February 2016]

Miles, M.B., Huberman, M.A., and Saldaña, J., 2014. Qualitative Data Analysis. 3ed. Sage

Monö, R., 1997. Design for Product Understanding. Liber AB, Trelleborg.

Neumier, M., 2003. The Brand Gap: How to Bridge the Distance between Business strategy and Design. Indianapolis, New Riders.

Peirce, C.S., 1955. Philosophical writings of Peirce. (J. Buchler, Ed.), Dover: Dover publications.

Persson, M., and Åström, P., 2006. Managerial issues in modularising complex products. Technovation, Volume 26, p.1201-1209, Elsevier Ltd.

Person, O., Schoormans, J., Snelders, D., and Karjalainen T-M., 2007. Should new products look similar or different? The influence of the market environment on strategic product styling. Design studies, Volume 29, Issue 1, p.30-48, Elsevier Ltd.

Ranscombe, C., Hicks, B., and Mullineux, G., 2012. A method for exploring similarities and visual references to brand in the appearance of mature mass-market products. Design studies, Volume 33, Issue 5, p.496-520. Elsevier Ltd. 
Sanchez, R., 2002. Using modularity to manage the interactions of technical and industrial design. Design Management Journal, Volume 2, Issue 1, p.8-19.

Scania, 2015. Exterior Cabs. [image online] Available at: <http:// www.scania.se/lastbilar/main-components/cabs/exterior/> [Accessed 20 October 2015]

Schön, D., 1987. Educating the reflective practitioner. John Wiley \& Sons, A Wiley Imprint

Sengers, P., Boehner, K., David, S., and Kaye, J., 2005. Reflective Design. Aarhus'05 21-25 August, 2005, Århus, Denmark.

Schoormans, J., and Robben, H., 1997. The effect of new package design on product attention, categorization and evaluation. Journal of Economic Psychology, Volume 18, Issues 2-3, p.271-287, Elsevier.

Solomon, O., 1988. Semiotics and marketing: New directions in industrial design applications. International Journal of Research in Marketing, Volume 4, p.201-215, Elsevier B.V.

The Economist, 2011. A checkered story [online] Available at: <http:// www.economist.com/node/17963363?story_id=17963363> [Accessed 24 April 2016]

Ulrich, K., 1995. The role of product architecture in the manufacturing firm. Research Policy, Volume 24, Issue 3, p.419-440.

Ulrich, K., and Eppinger 2012. Product Design and Development. 5ed. McGraw-Hill, Singapore

Volvo Cars, 2016a. About Volvo Cars. [online] Available at: <http:// www.volvocars.com/se/om-volvo/foretaget/om-volvo-cars> [Accessed 21 October 2015] 
Volvo Cars, 2016b. Build your own Volvo. [image online] Available at: $<$ http://byggdinvolvo.volvocars.se/\#/series> [Accessed 21 October 2015]

Warell, A., 2002. Design Syntactics: A functional Approach to Visual Product Form - Theory, Models, and Methods. PhD. Chalmers University of Technology, Gothenburg

Warell, A., 2006. Identity Recognition in product Design: An Approach for Design Management, proceedings of the 13th International Product Development Management Conference. Milan: Politecnico di Milano.

Wikipedia, 2016. Do it yourself. [online] Available at: <https:// en.wikipedia.org/wiki/Do_it_yourself> [Accessed 22 April 2016]

Yin, R., 2003. Case study research: Design and methods. 3ed. Thousand Oaks, CA: Sage. 



\section{Papers}

The articles associated with this thesis have been removed for copyright reasons. For more details about these see:

http://urn.kb.se/resolve?urn=urn:nbn:se:liu:diva-129551 